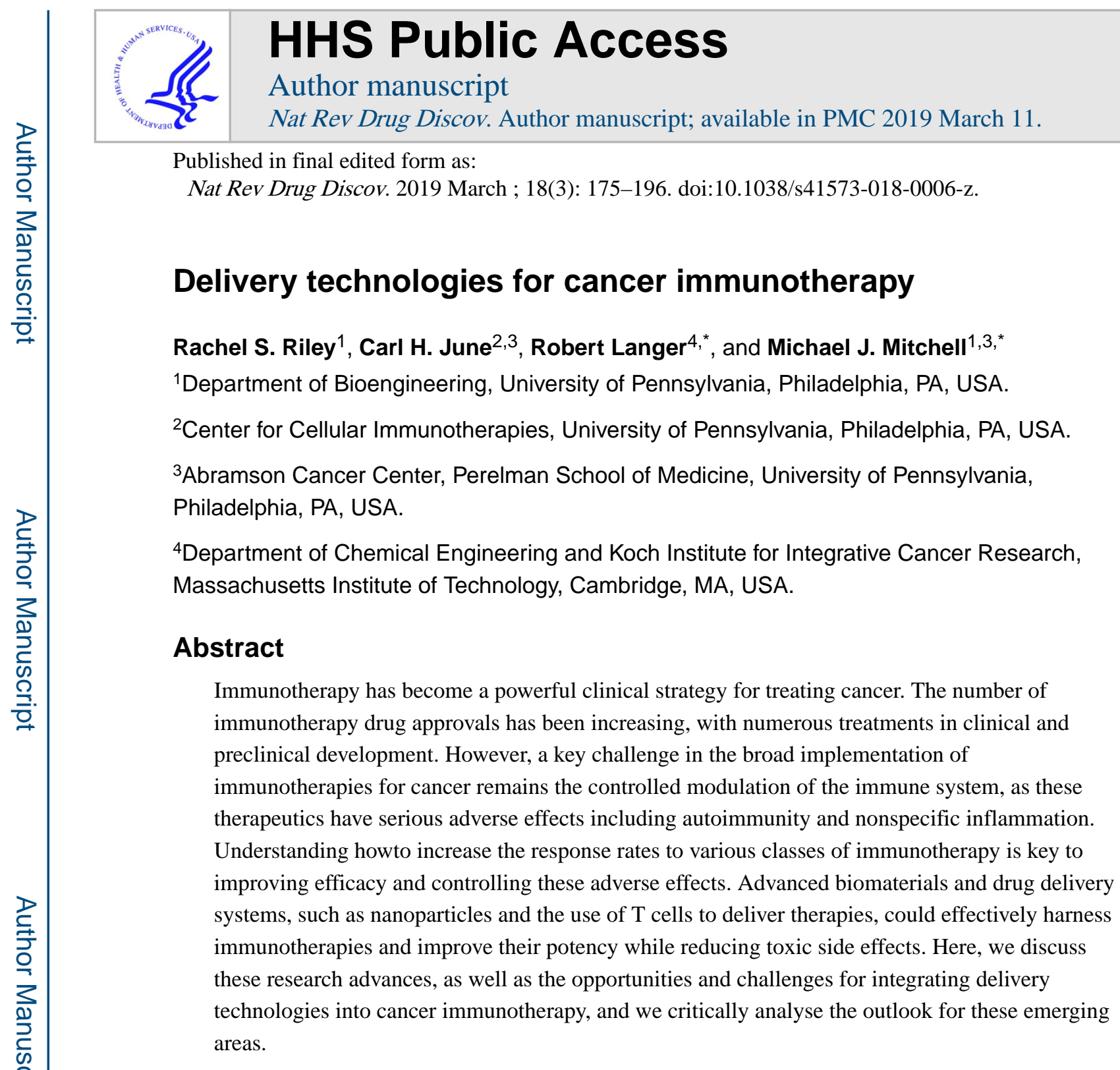

Cancer immunotherapy has shifted the paradigm for the treatment of cancer; these therapies aim to improve antitumour immune responses with fewer off-target effects than chemotherapies and other agents that directly kill cancer cells ${ }^{1-3}$. In cancer immunotherapy, agents are used to activate or boost the activation of the immune system to attack cancer cells through natural mechanisms, many of which are evaded during disease progression ${ }^{1-3}$.

\footnotetext{
* rlanger@mit.edu; mjmitch@seas.upenn.edu.

Author contributions

R.S.R., C.H.J., R.L. and M.J.M. conceived the ideas, researched the data for the manuscript, discussed the manuscript content and wrote the manuscript. M.J.M. and R.S.R. designed the display items. All authors reviewed and edited the article before submission. Competing interests

R.L. receives royalties from patents (as part of Massachusetts Institute of Technology (MIT) disbursements) that MIT has licensed or holds equity or receives consulting fees from Pfizer, Translate Bio, Editas, SQZ Biotech, Capio Biosciences, Combined Therapeutics, Moderna Therapeutics, Rubius Therapeutics, Tarveda Therapeutics and Verseau Therapeutics. C.H.J. works under a research collaboration involving the University of Pennsylvania and the Novartis Institutes of Biomedical Research, Inc. C.H.J. is an inventor of intellectual property licensed by the University of Pennsylvania to Novartis. C.H.J. has sponsored research and equity from Tmunity Therapeutics. C.H.J. is a consultant for Immune Design, Viracta and Carisma.

Publisher's note

Springer Nature remains neutral with regard to jurisdictional claims in published maps and institutional affiliations.
} 
Thus, immunotherapy is recognized as a promising strategy to treat, and even cure, certain types of cancer.

The first marketed immunotherapies for cancer were recombinant versions of the cytokine interferon-a (IFNa), which were approved by the US Food and Drug Administration (FDA) in 1986 for hairy cell leukaemia ${ }^{1}$ (TABLE 1 ). Some patients who were treated in these early clinical trials experienced partial remission, but IFNa was quickly replaced by purine analogues as a frontline therapy for hairy cell leukaemia because of the short therapeutic duration of IFNa ${ }^{2}$. Shortly thereafter, recombinant interleukin-2 (IL-2) was investigated as an immunotherapy for cancer and was approved by the FDA for metastatic renal cancer in 1992 and for metastatic melanoma in $1998\left(\mathrm{REF}^{3}\right)$. IL-2 therapy was initially met with great enthusiasm because its use resulted in durable complete responses in some patients ${ }^{4}$. However, high doses were required because of the short half-life of IL-2, which led to serious adverse effects including cytokine release syndrome and vascular leak syndrome, among others ${ }^{5-7}$. Although the early clinical investigations of these therapies were promising, progress in the field of cancer immunotherapy stalled in the 2000s owing in large part to the failure of many vaccine clinical trials ${ }^{8}$.

Following nearly a decade of relatively unsuccessful vaccine trials, the first successful therapeutic cancer vaccine, sipuleucel-T (an autologous dendritic cell therapy), was approved for prostate cancer in 2010, but its clinical translation was hampered by production complexities and other issues ${ }^{9,10}$. Shortly thereafter, the pioneering checkpoint inhibitor ipilimumab, a monoclonal antibody (mAb) that targets cytotoxic $\mathrm{T}$ lymphocyte antigen 4 (CTLA4), was approved for advanced melanoma in 2011 (REF. ${ }^{11}$ ). Over the past several years, novel immunotherapies - including other checkpoint inhibitor mAbs that target programmed cell death 1 (PD-1) or its ligand, PD-1 ligand 1 (PD-L1) ${ }^{12}$, as well as the first chimeric antigen receptor (CAR) T cell therapies ${ }^{13-16}$ — have been developed and approved for clinical use. The advent of ipilimumab and CAR T cell therapies was a turning point in cancer immunotherapy, as highlighted by Science as the breakthrough of the year in 2013 $\left(\right.$ REF. $\left.{ }^{17}\right)$. There are now over a dozen immunotherapies approved for cancer treatment (TABLE 1), and many more are in clinical trials. These immunotherapies fall into several classes, including checkpoint inhibitors, lymphocyte-activating cytokines, CAR T cells and other cellular therapies, agonistic antibodies against co-stimulatory receptors, cancer vaccines, oncolytic viruses and bispecific antibodies.

Despite these major advances, the clinical use of immunotherapies faces several challenges related to both efficacy and safety. With regard to efficacy, only subsets of patients respond to immunotherapies, making it difficult to predict patient responses ${ }^{18}$. Furthermore, there is great interest in developing patient-specific immunotherapies based on biomarker expression on cancer cells and in evaluating combination treatment strategies to improve response rates $^{19-21}$. Lastly, most immunotherapies were originally evaluated in haematological cancers owing to the delivery barriers faced by solid tumours, such as their compact tumour microenvironments. Recently, several immunotherapies, including activating cytokines and mAbs for checkpoint blockade, have been approved by the FDA for solid tumour therapy ${ }^{22}$. Of note, CAR T cell therapies have not yet been approved by the FDA for solid tumours, but researchers are developing CAR T cells that have high specificity towards cells in solid 
tumours ${ }^{23,24}$. With regard to safety, immunotherapy can induce autoimmune side effects in some patients, leading to attacks on healthy tissues. As observed with IL-2 therapy, many immunotherapies cause cytokine release syndrome and vascular leak syndrome, which lead to severe hypotension, fever, renal dysfunction and other adverse effects that are potentially lethal ${ }^{4,25,26}$.

Novel approaches to administering cancer immunotherapy in a safer, more controlled manner could extend the curative potential of these therapeutic agents to a broader range of patients and could also reduce toxicities. In particular, improved delivery technologies could increase the accumulation of immunotherapies within diseased tissues, enable more effective targeting of the desired tumour and/or immune cells and reduce off-target adverse effects. Research is ongoing to develop novel delivery platforms for immunotherapies, including nanoparticles, implants, scaffolds, biomaterials and cell-based platforms ${ }^{27}$ (TABLE 2). Several materials, including lipids, polymers and metals, have been utilized to develop delivery technologies, and we refer readers to published articles that specifically discuss the use of such materials ${ }^{28,29}$. Delivery platforms provide many benefits over the therapeutic agents alone $e^{30,31}$, and throughout this article, we describe precisely how these platforms can be utilized for safer and more effective cancer immunotherapy. First, they can be engineered to protect therapeutic cargo until it is delivered to the targeted cells ${ }^{32}$. Second, delivery systems can enable spatiotemporal control over therapeutics if they are responsive to stimuli such as $\mathrm{pH}$, light or ultrasound, thereby keeping the cargo inactive until it accumulates within target cells ${ }^{33-35}$. Finally, delivery platforms such as implants have been developed for localized, controlled delivery of drugs, and cell therapies have been developed to minimize toxicities associated with systemic administration ${ }^{36-38}$.

In this Review, we provide a brief overview of several of the main classes of cancer immunotherapy and include their clinical status, advantages and disadvantages. We then focus on novel delivery platforms that have been developed to overcome the challenges faced in the clinical translation of immunotherapies. Our overarching goal throughout this article is to provide insights into how to engineer delivery platforms that have the potential to improve the efficacy and safety of immunotherapies to ultimately improve patient outcomes.

\section{Classes of cancer immunotherapy}

This article discusses delivery systems for immunotherapies that fit into one or more of the following five classes: checkpoint inhibitors, lymphocyte-promoting cytokines, engineered $\mathrm{T}$ cells such as CAR T and T cell receptor (TCR) T cells, agonistic antibodies against costimulatory receptors, and cancer vaccines. Importantly, there are other emerging approaches to immunotherapy such as oncolytic viruses and bispecific antibodies that are not discussed in detail here (TABLE 1); for these topics, readers are referred to other published review articles ${ }^{39,40}$. In this section, we provide a brief overview of each of these five classes and highlight limitations that could potentially be addressed through the development of advanced delivery technologies. 


\section{Checkpoint inhibitors.}

Checkpoint inhibitors are the most thoroughly investigated class of immunotherapy to date. The two most common checkpoint inhibition strategies are PD-1/PD-L1 blockade and CTLA4 inhibition. Other checkpoint inhibitors in earlier phases of clinical development are reviewed in detail elsewhere ${ }^{41-43}$.

Physiologically, immune checkpoints maintain appropriate immune responses and protect healthy tissues from immune attack ${ }^{41}$. When $\mathrm{T}$ cells become activated - for example, in response to inflammation - they express PD-1, which enables them to recognize abnormal and cancerous cells $\mathrm{s}^{4,45}$. To evade recognition and elimination by $\mathrm{T}$ cells, tumour cells express PD-L1, which binds to PD-1 on T cells to render those cells inactive ${ }^{44,46}$. Therefore, blocking this interaction with mAbs that target either PD-1 or PD-L1 enables T cellmediated tumour cell death. Another immune checkpoint, CTLA4, is a co-inhibitory molecule that regulates the extent of T cell activation. Interactions between CTLA4 and its ligands - CD80 and CD86 - inhibit T cell activity and thus promote tumour progression ${ }^{42}$. By blocking the interaction between CTLA4 and these ligands, T cells remain active and can recognize and kill tumour cells. It is important to note, however, that the precise cellular mechanisms underlying CTLA4 blockade remain under investigation, and each of the CTLA4-targeted antibodies has different properties ${ }^{47}$. For example, some antiCTLA4 antibodies may both deplete regulatory T cells and inhibit checkpoint functionality 48,49 .

The clinical impact of PD-1, PD-L1 or CTLA4 checkpoint blockade strategies has grown considerably over the past few years. So far, five PD-1 or PD-L1 inhibitors and one CTLA4 inhibitor have been approved to treat various cancers based on improvements in overall survival compared with traditional chemotherapies ${ }^{50}$ (TABLE 1), and many trials involving checkpoint inhibitors in combination with chemotherapy or other targeted agents (>700 trials) are ongoing. Nevertheless, their use has several key limitations. As mentioned above, systemically administered checkpoint inhibitors can have severe side effects in numerous organs ${ }^{26,51-53}$. Second, many patients do not respond to treatment with checkpoint inhibitors. Factors underlying responsiveness to checkpoint inhibitors are being intensely studied $^{18}$ and may include low numbers of tumour-infiltrating $\mathrm{T}$ cells, deregulation of checkpoints in both tumour cells and T cells, and adapted resistance to checkpoint inhibition ${ }^{54-56}$. Additionally, different tumour microenvironments have distinct mechanisms of immunosuppression that require novel approaches for successful treatments ${ }^{57}$. These limitations, and others, can be addressed by advanced delivery technologies, as described below.

\section{Cytokines.}

Cytokines were the first class of immunotherapy to be introduced into the clinic, with the approval of recombinant IFNa therapies in 1986 (REF. ${ }^{1}$ ). This strategy differs from checkpoint blockade approaches because injected cytokines directly stimulate the growth and activity of immune cells. The three main types of cytokine that have been pursued for immunotherapy are interferons, interleukins and granulocyte-macrophage colonystimulating factor (GM-CSF) ${ }^{4}$. Interferons are normally produced by immune cells in 
response to microbial pathogens and elicit immune responses by inducing the maturation of numerous immune cells including macrophages, natural killer (NK) cells, lymphocytes and dendritic cells ${ }^{58-61}$. Interferon activation of immune cells can also inhibit angiogenesis in the extracellular tumour space ${ }^{4,59,62}$. Interleukins stimulate the activity and growth of CD4 ${ }^{+}$ $\mathrm{T}$ cells and $\mathrm{CD} 8^{+} \mathrm{T}$ cells ${ }^{63-66}$. Finally, GM-CSF improves immune responses through two mechanisms: promoting $\mathrm{T}$ cell homeostasis, which improves $\mathrm{T}$ cell survival, and supporting dendritic cell differentiation so that these cells express tumour-specific antigens ${ }^{67}$. Both granulocyte colony-stimulating factor (G-CSF) and GM-CSF have been used to augment and accelerate granulocyte recovery after chemotherapy, but GM-CSF may be more proinflammatory than G-CSF ${ }^{67-69}$. In addition to these widely studied cytokines, researchers are also investigating agonists that activate immune cells via intracellular mechanisms. For example, TGF $\beta$ receptor type 1 (TGF $\beta$ R1) inhibitors, such as SD-208, restore T cell function and improve immune responses ${ }^{70}$. Additionally, small-molecule agonists of TLR7/ TLR8 directly activate antigen-presenting cells (APCs) to promote antitumour activity, and stimulator of interferon genes (STING) agonists have been used to induce pro-inflammatory cytokine production and other type I interferon responses ${ }^{71,72}$.

Three immune-activating recombinant cytokines are approved for cancer immunotherapy (TABLE 1), and several more, including IL-17 and IL-15 (REFS ${ }^{73,74}$ ), are in clinical development. However, owing to their somewhat short half-life, treatments generally consist of high-dose bolus injections that cause vascular leakage and cytokine release syndrome ${ }^{4}$. Furthermore, cytokine therapy can promote the survival of regulatory $\mathrm{T}$ cells and induce death in stimulated $\mathrm{T}$ cells, ultimately causing an autoimmune attack against healthy tissues $^{25}$. The use of IL-15 and IL-21 may have some advantages over IL-2 in these respects ${ }^{75,76}$. Current research and clinical trials are investigating their use in combination treatment strategies with two or more cytokines (for example, interleukins and interferons together) or with checkpoint inhibitors or chemotherapies to reduce the adverse effects of high treatment dosages that are required for the therapies if used independently ${ }^{59}$.

\section{Engineered $\mathrm{T}$ cells: chimeric antigen receptor $\mathrm{T}$ and $\mathrm{T}$ cell receptor $\mathrm{T}$ cells.}

Recently, CAR T cells have gained attention from their clinical successes and expedited FDA approvals. In the CAR T cell approach, $\mathrm{T}$ cells are collected from patient blood and are then genetically engineered to express CARs that are specific for an antigen present on tumour cells. These engineered $\mathrm{T}$ cells are then re-administered to the same patient. Upon injection, CAR T cells recognize the targeted antigen on tumour cells to induce tumour cell death ${ }^{77}$. Unlike other treatment options, CAR T cells are typically a onetime therapy, and the cells can retain their activity for over a decade after injection ${ }^{13,78}$. Many patients achieve remission and prolonged survival, but the long-term effects of CAR T cell therapy remain under investigation ${ }^{14,79}$. Furthermore, the production of CAR T cells is expensive, technically complex, and time intensive, all of which are major considerations for the widespread implementation of CAR T cell therapies ${ }^{80}$. In addition, in some circumstances (particularly solid tumours with harsh microenvironments), the infused cells do not persist, so combination therapies and novel drug delivery systems are needed to improve $\mathrm{T}$ cell survival. 
The initial target for CAR T cells was CD19 because this molecule is frequently expressed on B cell leukaemias and lymphomas. CD19 expression in normal tissues is confined to the B cell lineage, so any on-target, off-tumour activity would be limited by B cell aplasia, a side effect that can be mitigated with immunoglobulin replacement therapy ${ }^{81}$. Currently, two CD19-targeting CAR T cell therapies are approved for clinical use by the FDA:

axicabtagene ciloleucel for diffuse large B cell lymphoma and tisagenlecleucel for acute lymphoblastic leukaemia and diffuse large B cell lymphoma ${ }^{82,83}$. The clinical success of CD19 CAR T cells has encouraged many efforts to engineer CAR T cells that target different antigens, or a combination of several antigens, for a more generalizable approach to cancer therapy ${ }^{77,84-88}$. However, these efforts are met with two key challenges. First, both CAR T and TCR T cells can cause cytokine release syndrome and neurotoxicity ${ }^{89,90}$. The second issue is how to enable these engineered cells to have efficacy in solid tumours ${ }^{85,91,92}$. Thus far, in the few solid tumours that have been successfully treated with CAR T cells, such as EGFRvIII-expressing glioblastoma ${ }^{85}$, the target antigen is expressed at vastly higher levels on tumour cells compared with normal cells.

TCR T cells are engineered cells that are being tested in clinical trials for both haematological and solid cancers. TCRs respond to tumour-associated intracellular antigens presented by major histocompatibility complexes (MHCs) ${ }^{93}$. The choice of antigenic target for TCR T cells can be shared antigens, such as cancer-testis antigens, or patient-specific neoantigens that result from tumour mutations ${ }^{94}$. Unlike MHC-independent CAR T cells, TCR T cells must be MHC-matched with the patient. Preclinical investigations of TCR T cells indicate that the specificity of the infused $\mathrm{T}$ cells is of paramount importance ${ }^{95}$. Furthermore, the results from initial trials with TCR T cells suggest that toxicity from T cells that use high-affinity TCRs is difficult to predict ${ }^{96}$. Researchers are developing novel delivery technologies to overcome the toxicities associated with both CAR T cells and TCR $\mathrm{T}$ cells and improve their applicability for solid tumours, as described below.

\section{Co-stimulatory receptor agonists.}

Agonistic antibodies are designed to specifically bind to receptors on the surface of $\mathrm{T}$ cells and trigger intracellular signalling pathways that induce $\mathrm{T}$ cell growth, survival and effector function against tumour cells ${ }^{97}$. The most commonly targeted $\mathrm{T}$ cell receptors are costimulatory receptors (namely CD28) and several members of the tumour necrosis factor receptor (TNFR) family, such as 4-1BB (also known as TNFRSF9 or CD137), OX40 (also known as TNFRSF4) and glucocorticoid-induced TNFR-related protein (GITR; also known as TNFRSF18), that are expressed on the surface of APCs ${ }^{98}$. Ligand binding to these costimulatory receptors triggers intracellular cell signalling that promotes $\mathrm{T}$ cell growth and anticancer activity ${ }^{25,99}$. Ligand binding to the TNFR family members likely acts through the NL- $\mathrm{BB}, \mathrm{JNK}$ and PI3K-PKB (also known as AKT) pathways ${ }^{98}$, which are implicated in cell survival, proliferation and effector function.

Agonistic antibodies are at an earlier stage of development than other classes of immunotherapy discussed in this Review, as there are none approved by the FDA. Nevertheless, several agonistic antibodies that target different receptors have reached clinical trials. At present, the furthest advanced candidates are in phase II trials: two agonistic 
antibodies that target 4-IBB (utomilumab and urelumab ${ }^{100,101}$ ) and several that target OX40 (PF-04518600, BMS-986178 and INCAGN-01949, among others) ${ }^{102}$. Thus far, studies have shown that agonistic antibodies have dose-limiting toxicities similar to those for cytokines, as they can induce activity in undesired subtypes of immune cells and immune activity towards healthy cells ${ }^{98}$. Furthermore, certain agonistic antibodies induce regulatory $\mathrm{T}$ cell activity ${ }^{103}$. Ongoing clinical trials are evaluating the toxicities associated with specific dosages and administration schedules, and delivery platforms are being developed to address these concerns. For example, anti-4-1BB antibodies anchored to liposomal nanoparticles have more intratumoural accumulation and lower toxicities than freely delivered antibodies in both subcutaneous and intravenous lung metastasis mouse models ${ }^{104}$. Future studies should specifically address how delivery platforms for agonistic antibodies can enable control over exposure duration while still inducing multivalent $\mathrm{T}$ cell activation.

\section{Cancer vaccines.}

Types of cancer vaccine include tumour cell lysate, dendritic cells, nucleic acids (such as mRNA) or neo-antigens ${ }^{105}$. For brevity, here we discuss the latter three, and we refer readers to published review articles for information on tumour cell lysate-derived vaccines ${ }^{106,107}$. Dendritic cell vaccines are the most commonly studied class of cell-based cancer vaccine ${ }^{55}$. Dendritic cell vaccines are made from dendritic cells collected from patients that are engineered to express tumour-associated antigens and thus directly activate $\mathrm{T}$ cells to attack cancer cells ${ }^{55}$. As noted above, one dendritic cell vaccine, sipuleucel-T, was approved to treat prostate cancer in 2010 on the basis of its ability to prolong overall survival ${ }^{9,108}$. Although other dendritic cell-based vaccines have demonstrated high safety profiles, they have failed in clinical trials owing to lack of efficacy ${ }^{8}$. It is anticipated that efficacy can be improved by identifying particular subsets of dendritic cells that express high levels of targeted antigens ${ }^{55}$ and by improving delivery to the relevant lymph nodes ${ }^{55,109,110}$.

Nucleic acid therapeutics, such as DNA-based or RNA-based vaccines, have emerged as promising alternatives to conventional vaccines and rely on the intracellular delivery of exogenous nucleic acids into target cells ${ }^{111}$. In these technologies, DNA or mRNA is taken up by APCs and translated to induce antigen expression. The targeted antigens are presented to $\mathrm{T}$ cells to induce their activation against tumour cells that express the antigen of interest $^{111}$. DNA vaccines have been tested in a number of clinical trials, but they are often unsuccessful because of nuclear delivery barriers and immunogenicity ${ }^{112-114}$. Alternatively, mRNA-based cancer vaccines have been developed to directly induce APCs to express antigens that are implicated in immune recognition ${ }^{111}$. Because mRNA is a naturally occurring molecule, it can be easily produced, and its half-life can be extended with modifications. mRNA is also non-infectious and does not integrate into the genome as many DNA vaccines do ${ }^{111,115}$. However, mRNA is quickly degraded by nucleases and cannot easily be internalized by cells, so it requires the use of transfection agents or delivery platforms to mediate intracellular delivery ${ }^{111,116}$. Thus, nucleic acid vaccines can greatly benefit from delivery technologies that improve intracellular (for mRNA) or intranuclear (for DNA) delivery. 
Neoantigen vaccines are being investigated as cancer immunotherapies for their ability to boost the immune response to cancer cells ${ }^{117,118}$. Neoantigens are tumour-specific antigens that arise from somatic DNA alterations in cancer cells, and one main benefit of using neoantigens is that they are present only in cancer cells, so off-target adverse effects are virtually eliminated ${ }^{117}$. Furthermore, these vaccines can encompass an unlimited number of neoantigens, which is ideal for treating heterogeneous cancers. Delivery platforms can improve upon the success of both mRNA and neoantigen vaccines by improving the stability of the encapsulated molecules and by harbouring several mRNA sequences or neoantigens within one platform for a comprehensive approach to treat heterogeneous cancers, as described below ${ }^{119,120}$.

\section{Need for novel delivery technologies}

The five classes of immunotherapy described here each face delivery challenges, some of which are shared and others of which are class-specific. Checkpoint inhibitors, cytokines and agonistic antibodies have similar delivery challenges. The success of these therapies relies on their interaction with the targeted protein. A major limitation of their use is that they produce substantial autoimmunity, leading to adverse effects that limit the allowable administered doses ${ }^{26}$. For this reason, a central goal in the development of delivery technologies for these therapies is to enable targeted and controlled release so that the therapies are primarily active in the desired cell types, which should minimize off-target effects.

The microenvironment in many solid tumours is a challenge to the broad implementation of all the immunotherapy classes discussed here ${ }^{121}$. For example, the microenvironment of solid tumours can be categorized as either immunologically 'hot' (high immunogenicity) or 'cold' (low immunogenicity), which have either high or low levels of cytotoxic lymphocyte infiltration within the tumour space, respectively ${ }^{121}$. This key difference in the composition of the microenvironment suggests that tumours with high immunogenicity exhibit stronger responses to checkpoint inhibitors than do tumours with low immunogenicity ${ }^{121}$. Delivery technologies can therefore be exploited to modulate immunogenicity in cold tumours. In addition, because delivery platforms can also reduce the systemic toxicity of immunotherapies by limiting drug exposure to particular tissues ${ }^{25,122}$, they can be used to deliver combinations of therapeutics that would otherwise be too toxic to administer to patients. In an elegant example of this combination effect, liposomal nanoparticles were complexed with a PD-L1 trap plasmid (to block PD-L1 signalling) and cationic protamines to form lipid-protamine-DNA (LPD) nanoparticles that are targeted to tumour tissue using aminoethyl anisamide ligands ${ }^{122}$. Mice bearing orthotopic colorectal tumours were intravenously injected with both the LPD nanoparticles and the chemotherapy drug oxaliplatin, which has been shown to activate dendritic cells and induce immune activity in tumours in addition to its DNA-damaging effects in tumour cells ${ }^{122}$. Thus, oxaliplatin may cause immunologically cold tumours to become hot and therefore susceptible to LPD therapy. The tumour-targeted LPD nanoparticles and oxaliplatin worked synergistically to inhibit tumour growth and exhibited reduced toxicity compared with that seen in mice treated with PD-L1 antibodies and oxaliplatin with no nanoparticle carrier ${ }^{122}$. This 
demonstrates that nanoparticles can potentially enable combination treatment strategies to make tumours with low immunogenicity susceptible to immunotherapy.

In addition to enabling combination treatment strategies, nanomedicines can be designed to respond to the tumour microenvironment and increase penetration at those sites ${ }^{123}$. In an interesting example of this, $100 \mathrm{~nm}$ nanoparticles composed of gelatin were coated with 10 $\mathrm{nm}$ quantum dots that were released upon exposure to matrix metalloproteinases (MMPs), which are often present in tumour microenvironments ${ }^{123}$. In this study, the nanoparticles were intratumourally injected into fibrosarcomas in a dorsal skin-fold window chamber model, and the quantum dots that were delivered on nanoparticles penetrated the tumour tissue substantially more than nonreactive quantum dots alone ${ }^{123}$. Thus, by replacing the quantum dots to generate therapeutic-loaded nanoparticles, this unique design could be exploited to deliver therapeutics through solid tumours with both high and low immunogenicity, the latter of which would otherwise not be susceptible to immunotherapy.

Delivery systems for immunotherapies that require intracellular delivery, such as some small-molecule agonists and genetic vaccines, must overcome extracellular and intracellular barriers with minimal systemic toxicity. Nucleic acids are negatively charged, and so they require a secondary agent, typically lipid or polymer transfection reagents, in order to be taken up by cells. Furthermore, DNA vaccines need to pass through both the cellular and nuclear membranes to be transcribed in the nucleus ${ }^{113}$. By contrast, mRNA requires penetration into only the cell cytosol for protein translation, but without modifications or delivery platforms, mRNA is quickly degraded by nucleases ${ }^{120}$. Delivery technologies for these vaccines protect nucleic acids from degradation and enable intracellular delivery without toxic transfection reagents. Nanoparticle delivery systems in particular must escape from endosomes inside cells to enter the cytoplasm and avoid exocytosis from late endosomes. In a recent study, 70\% of the small interfering RNA (siRNA) molecules encapsulated within lipid nanoparticles underwent exocytosis ${ }^{124}$. To disrupt endosomes and enable cytosolic delivery, ionizable and bioreducible materials can be specifically designed to degrade inside cells and facilitate the escape of nucleic acids from endosomes into the cytoplasm $^{125}$. Similar to nucleic acids, the use of intracellular agonists, such as those that target either TLR7/TLR8 or STING, is often limited to administration via intratumoural injection, as intravenous administration can lead to systemic toxicity ${ }^{126}$. Thus, delivery technologies for these innate immune system agonists and other immunotherapies that require intracellular delivery should aim to encapsulate and protect the therapeutic cargo until it can be released into the cytosol of target cells. Below, we describe a range of delivery technologies that have recently been developed to improve the safety and efficacy of cancer immunotherapies, and we discuss the anticipated clinical impact of these delivery systems $9,23,87,127-130$.

\section{Delivery strategies for immunotherapy}

For decades, it has been thought that selective nanomedicine delivery to tumours could exploit an enhanced permeability and retention (EPR) effect - characterized by the greater permeability of tumour vessels than normal vessels to macromolecules and the retention of macromolecules in tumours owing to poor lymphatic clearance ${ }^{131-133}$ (FIG. 1a). Although 
the EPR effect is pronounced in preclinical models of solid tumours that exhibit leaky vasculature and is also observed in humans, the potential to harness it therapeutically in patients with cancer remains unclear, and most nanotherapeutics investigated in clinical trials have not demonstrated substantial benefits over conventional chemotherapy ${ }^{134,135}$. A meta-analysis of 117 studies of nanomedicine delivery, some of which relied on either the EPR effect or active targeting of cancer cells, showed that only $0.7 \%$ (median) of administered nanoparticles reach tumours ${ }^{136}$. Magnetic resonance imaging (MRI) or positron emission tomography (PET) studies to assess the role of the EPR effect in tumours revealed high variability of solid tumour permeability both between patients and between tumours in individual patients ${ }^{137,138}$. These findings demonstrate the importance of understanding the physical microenvironment of tumours and their permeability in order to optimally engineer delivery systems for tumour penetration and uptake.

Importantly, different routes of administration can influence the therapeutic efficacy of delivery technologies. For example, local delivery using intratumoural injections or implantable scaffolds may result in higher accumulation of drugs in tumours, but it may not be feasible for tumours that are not easily accessible. Thus, the route of administration is an important consideration when evaluating delivery technologies for immunotherapies for specific types of cancer. A simple approach to improve biodistribution is to conjugate polyethylene glycol (PEG) to therapeutic agents, such as cytokines, to improve half-life and stability; this technique is being investigated in clinical trials ${ }^{4,139}$. However, PEGylation is not selective for tumour tissue and is still limited by off-target effects. As an alternative way to selectively deliver drugs (typically cytotoxic therapies) to tumours, nanoparticles have been designed with the goal of directly targeting receptors on the surface of cancer cells ${ }^{134,140,141}$ (FIG. 1b). Although active targeting improves the retention of nanoparticles in tumours, it has not substantially improved biodistribution and localization of the nanoparticles within the tumour ${ }^{142}$. Beyond these approaches that rely on systemic administration, technologies for local delivery, such as injectable hydrogels, implantable biomaterials and microneedles, are also being explored ${ }^{37,143,144}$. Additionally, delivery technologies are being developed to directly target immune cells in the bloodstream (FIG. 1c). In this regard, nanoscale delivery systems have been designed for a range of immunotherapy applications, including the delivery of drugs directly to tumour-infiltrating immune cells in the bloodstream, mRNA cancer vaccine technologies that target dendritic cells in the spleen and nanoscale conjugates that accumulate immunotherapeutics within lymph nodes and the extracellular matrix. Below, we describe novel delivery platforms that utilize each of these strategies, and others, for improving immunotherapy.

\section{Nanoparticles and conjugates}

\section{Nanoparticles targeting T cells in blood.}

Nanoparticle-based approaches have recently been designed to target immunotherapeutic agents directly to $\mathrm{T}$ cells ${ }^{145}$. Immune cells such as $\mathrm{T}$ cells can migrate actively into tumours, leveraging chemokine gradients to traffic to sites of inflammation within tumours ${ }^{146}$. In contrast to delivering cytotoxic agents to tumour cells, which requires nanoparticles to kill most or all of the target cells to be effective, lower concentrations of immune-stimulating 
drugs can be used to stimulate or amplify a T cell response. In one approach, the FDAapproved polymers poly(lactic-co-glycolic acid) (PLGA) and PEG were used to synthesize nanoparticles encapsulating either SD-208, a TGF $\beta$ R 1 inhibitor, to restore T cell function, or a TLR7/TLR8 agonist to recruit lymphocytes to non-inflamed tumours ${ }^{145}$. Antibody fragments were conjugated to the surface of nanoparticles via thiolmaleimide click chemistry, such that the nanoparticles bound PD-1-expressing T cells in the circulation and in tumours ${ }^{145}$. Targeting TGF $\beta$ R 1 inhibitors to T cells using nanoparticles extended survival in a mouse model of colorectal cancer compared with free drugs at similar dosages, and targeted delivery of the TLR7/TLR8 agonist increased the proportion of tumour-infiltrating $\mathrm{CD} 8{ }^{+} \mathrm{T}$ cells and sensitized tumours to anti-PD- 1 therapy ${ }^{145}$. Collectively, targeting the delivery of nanoparticle-based immunotherapies to tumour-infiltrating immune cells in blood, rather than targeting tumour cells directly, is a potentially attractive means to improve immunotherapeutic localization in tumours and to stimulate an antitumour response.

\section{Vascular receptor-mediated adhesion of drugs to immune cells.}

Liposome-based drug delivery systems have been developed to bind immune cells in the circulation by leveraging receptor-ligand interactions based on those between immune cells and the inflamed endothelium ${ }^{147,148}$. In two examples, liposomes were functionalized with the vascular adhesion receptor E-selectin alone or together with the immune cytokine TRAIL (also known as TNFSF10) to selectively induce tumour cell apoptosis ${ }^{147-149}$. Ligands for E-selectin are expressed on both circulating tumour cells and immune cells, and TRAIL engages death receptors on the surface of cancer cells to induce apoptosis. In vivo, the E-selectin-TRAIL nanoparticles bound to immune cells in blood with negligible side effects $^{147}$, and the half-life of TRAIL was substantially increased because it was tethered to the surface of immune cells ${ }^{148}$. These nanoparticle-coated immune cells were initially utilized to target and kill circulating tumour cells in the bloodstream to reduce metastatic tumour formation, and they killed most of these cells within 2 hours ${ }^{147}$. This approach also reduced the overall tumour burden in a murine model of prostate cancer, indicating that tumour-infiltrating immune cells likely migrate into solid tumours to deliver immune cytokines and induce antitumour responses ${ }^{148}$. Collectively, these results indicate that receptor-ligand interactions that occur within the vasculature can be exploited to deliver immune-based drugs to endogenous immune cells, which can then migrate into the tumour to deliver therapeutics.

\section{Nanoparticles for mRNA cancer vaccines.}

As noted above, mRNA vaccines are promising platforms for cancer immunotherapy ${ }^{111}$. However, their application has been limited by their instability and inefficient in vivo mRNA delivery ${ }^{150}$. The challenges to efficient in vivo delivery are numerous. mRNA vaccines must avoid degradation by endonucleases in physiological fluids and in the extracellular space and evade renal clearance via glomerular filtration. Furthermore, they need to diffuse through the compact extracellular matrix to reach the target cells ${ }^{151}$ and then be taken up and escape the endosome to release mRNA into the cytosol, where translation occurs ${ }^{152-154}$ (FIG. 2). Recently, delivery systems have been designed to overcome these biological barriers to in vivo mRNA delivery, as described below 155,156 . 
Two methods of improving mRNA delivery utilize viral or lipid-based formulations. Viral delivery systems, including lentiviruses, adeno-associated viruses and the Sendai virus, are capable of systemically delivering nucleic acids, including mRNA ${ }^{157,158}$. However, the use of viral delivery systems is limited, in part owing to the induction of unwanted immune responses ${ }^{159}$. As an alternative to viral delivery, non-viral systems comprising lipids and lipid-like materials have been efficacious in preclinical animal models as well as in initial clinical studies ${ }^{155,156}$ (FIG. 3a). In a recent study, a lipid-based nanoparticle mRNA vaccine was designed to target dendritic cells in vivo without the need for antibodies or adhesion ligands ${ }^{156}$. This platform comprises several off-the-shelf lipids that were used in the earliest nucleic acid delivery systems, including the cationic lipids DOTMA (1,2-di- $O$-octadecenyl-3-trimethylammonium-propane) and DOTAP (1,2-dioleoyl-3-trimethylammoniumpropane), as well as the zwitterionic lipid DOPE (1,2-dioleoyl-sn-glycero-3phosphoethanolamine), which form complexes with anionic mRNA ${ }^{160}$ (FIG. 3b). Rather than incorporating antibodies or ligands, alterations of the RNA-to-lipid ratio - and thus the surface charge of the nanoparticle formulation - improved intravenous mRNA delivery to dendritic cell-containing compartments in the spleen and lymphoid tissues of mice ${ }^{156}$. Interestingly, studies using nanoparticles containing mRNA that encodes a fluorescent protein showed that overall biodistribution in mice was more dependent on nanoparticle charge than on the lipid material used ${ }^{156}$. The lead nanoparticle candidate enabled dendritic cells to translate mRNA and subsequently express tumour antigens, present them to T cells and mediate potent rejection of tumours in murine models of melanoma and lung and colorectal cancer ${ }^{156}$. Of note, this platform is in clinical trials for melanoma therapy and has shown promising immune responses in patients ${ }^{156,161}$.

\section{Ionizable lipid nanoparticles for in vivo mRNA delivery.}

Although approaches utilizing cationic lipids have promising efficacy, they are both toxic and immunogenic. Intravenously injected cationic liposomes can cause liver damage ${ }^{162}$, destabilize the plasma membrane of non-targeted cells ${ }^{163}$ and induce inflammation ${ }^{164}$. Additionally, the positive charge of these lipids can be negated via adsorption of anionic serum proteins to liposomes, thereby reducing intracellular nucleic acid delivery ${ }^{163}$. As a means to overcome the challenges faced in using cationic lipids for mRNA-based immunotherapies, ionizable lipid-like materials have been designed to reduce the toxic side effects of cationic lipids while retaining their transfection characteristics ${ }^{155,165}$ (FIG. 3c). Ionizable lipids are positively charged at low $\mathrm{pH}$, which enables complexation with mRNA in nanoparticles in acidic buffers, and they are neutral at physiological $\mathrm{pH}$, which reduces toxicity compared with cationic lipids 150,165 . The positive charge from lipids also increases cellular uptake via endocytosis and subsequent nanoparticle deposition into endosomes, which reduce their $\mathrm{pH}$ (from $\sim 6.8$ to 4.5 ) as they transition into lysosomes ${ }^{166}$. Thus, it is believed that the positive charge of these ionizable lipids enables electrostatic interaction and fusion with the negatively charged endosomal membranes, leading to destabilization of the bilayer and subsequent release of nucleic acids into the cytosol. However, the precise mechanisms of endosomal release remain under investigation ${ }^{167-169}$.

In one critical study, a lipid nanoparticle formulation composed of an ionizable lipid, a phospholipid, cholesterol and a PEG-lipid conjugate was engineered for the delivery of 
mRNA vaccines to induce a cytotoxic $\mathrm{T}$ cell response ${ }^{155}$ (FIG. 3a). Upon subcutaneous administration, the nanoparticles successfully transfected a range of immune cells, including dendritic cells, macrophages and neutrophils, and accumulated in lymph nodes ${ }^{155}$. This technology was also evaluated in a murine model of melanoma, in which a single immunization with nanoparticles induced strong $\mathrm{CD} 8^{+} \mathrm{T}$ cell proliferation and functionality, as mice treated with these nanoparticles had extended survival compared with controls ${ }^{155}$. Furthermore, treatment of mice with nanoparticles that contained mRNA encoding the tumour antigens gp100 (also known as PMEL) and TRP2 (also known as DCT) resulted in overall tumour shrinkage and extended survival in an aggressive melanoma tumour model ${ }^{155}$. This study demonstrates the capacity of ionizable lipid nanoparticles to improve the delivery of mRNA vaccines and induce powerful immune responses.

Polymeric systems such as dendrimers have also been developed for mRNA vaccine delivery ${ }^{170,171}$. These systems have been utilized to deliver large therapeutic payloads such as replicon mRNA, which can substantially amplify the production of encoded protein. This was demonstrated in various applications including vaccines for H1N1 influenza,

Toxoplasma gondii and Ebola virus ${ }^{170,171}$. These technologies should now be evaluated for their capacity to deliver replicon mRNA for the sustained production of tumour antigens.

\section{Bioinspired molecular conjugate subunit vaccines.}

Subunit vaccines contain purified peptides, proteins or polysaccharides in combination with molecular adjuvants that are designed to boost the immune response. These vaccines are easier to manufacture and potentially safer than live vaccines. However, subunit vaccines typically elicit weaker immune responses than live pathogens in part because of inefficient antigen and adjuvant delivery to secondary lymphoid organs, where immune responses are coordinated ${ }^{30,172}$. Improving the adjuvant effect of subunit vaccines is a promising means to improve the immune response in these systems, and this strategy has been previously reviewed in detail ${ }^{173}$. Molecular conjugates that target dendritic cells in the draining lymph nodes are another attractive approach, but antibody-antigen conjugates designed for such purposes have been shown to drain into the bloodstream, thus reducing accumulation in lymph nodes ${ }^{174}$ (FIG. 3d). In an alternative strategy, vaccine conjugates were designed to increase the accumulation of subunit vaccines in draining lymph nodes ${ }^{175}$. These amphiphilic vaccines consist of an antigen or adjuvant conjugated to an albumin-binding lipophilic tail and linked using a functionalized PEG block ${ }^{175}$ (FIG. 3d). Compared with the free compounds, more of these conjugates accumulated in the lymph nodes, and drainage into the bloodstream was reduced. This accumulation induced a 30 -fold increase in $\mathrm{T}$ cell priming, improved antitumour efficacy in a murine model of melanoma and reduced systemic toxicity ${ }^{175}$.

Vaccine conjugates have also been incorporated into a combinatorial immunotherapy approach that includes a tumour antigen-targeting antibody, an engineered version of IL-2 with an extended half-life and an anti-PD-1 mAb ${ }^{176}$. This approach recruited numerous innate and adaptive immune cells - which even attacked tumour proteins not directly targeted by the cocktail itself - to eradicate large tumour burdens in genetically engineered mouse (GEM) models of melanoma or syngeneic tumour models ${ }^{176}$. Given both the 
improved targeting to lymph nodes and the simple conjugation of this approach, this platform can be applied to a broad range of subunit vaccines to increase their potency and reduce off-target toxicity.

\section{Matrix-binding checkpoint inhibitor conjugates.}

As a means to avoid the immune side effects associated with systemic administration of checkpoint inhibitors, matrix-binding molecular conjugates have been designed to be retained intratumourally and peritumourally and to reduce systemic drug exposure ${ }^{177}$. In one example, checkpoint inhibitors were bound to a peptide derived from placental growth factor 2 (PLGF2), which has an exceptionally high affinity for multiple matrix proteins, using a water-soluble, amine-to-sulfhydryl crosslinker ${ }^{177}$ (FIG. 3e). Following peritumoural administration, these conjugates remained more localized in the extracellular matrix near tumour tissue than unmodified inhibitors. This localization delayed tumour growth and prolonged survival in GEM models of melanoma and breast cancer ${ }^{177}$. Furthermore, these conjugates induced systemic antitumour immunity and reduced treatment-related toxicities that are commonly associated with systemic administration of checkpoint inhibitors. Importantly, engineering matrix-binding conjugates is scalable and, by means of intraperitoneal or peritumoural injection, enables local delivery of checkpoint inhibitors to additional tumour sites in the body that cannot easily be reached by systemic administration.

\section{Biomaterials: localized immunotherapy}

\section{Controlled release technologies.}

Although immunomodulatory antibodies can induce robust antitumour immune responses, systemic delivery of these agents can induce cytokine release syndrome and abnormal liver function ${ }^{178}$. To minimize off-tissue effects, delivery systems have been designed for local and sustained release in vivo. Early controlled release systems were composed of mineral oils and polymeric microspheres and were generally used for the local delivery of immunomodulatory antibodies ${ }^{179-182}$. More recent research has investigated controlled release technologies to reduce these toxicities, as discussed below.

In an interesting platform, Montanide ISA 51, a commercially available mixture of light mineral oils that has been used in immunotherapy clinical trials ${ }^{179}$, was used to prepare a sustained release formulation for local delivery of agonistic anti-CD40 antibodies ${ }^{181}$. Compared with systemic administration of free antibodies, local injection of this controlled release system required lower dosages of antibody to activate $\mathrm{T}$ cells and abrogated systemic toxicity. Furthermore, this platform eradicated local and secondary tumours in a mouse model of lymphoma ${ }^{181}$. An expanded study used Montanide ISA 51 to deliver anti-CTLA4 antibodies in a mouse model of colon cancer ${ }^{180}$. Importantly, ongoing clinical trials that study Montanide ISA 51 should provide valuable information on the pharmacokinetics and dosing regimens for specific cancers, as well as its efficacy in combination with adjuvants. Given that Montanide ISA 51 induces inflammation, swelling and granulomas at the injection site in mice ${ }^{183}$, biodegradable polymeric microparticle formulations have also been designed for local and sustained delivery of immunomodulatory antibodies ${ }^{182}$. In one study, a biodegradable polymer, poly(D,L-lactic-co-hydroxymethyl glycolic acid) (PLHMGA), was 
utilized to slowly release anti-CD40 and anti-CTLA4 antibodies in a mouse model of colon cancer ${ }^{182}$. PLHMGA is a hydrophilic polymer that is characterized by reduced acidification and thereby provides better protection from degradation and sustained release of encapsulated immunotherapeutics relative to other controlled release polymers such as $\mathrm{PLGA}^{182}$. Impressively, a local injection of PLHMGA microparticles (approximately 12-15 $\mu \mathrm{m}$ in diameter) enabled the controlled release of antibodies over 30 days, with comparable efficacy to antibodies formulated in incomplete Freund's adjuvant, which is similar in formulation to Montanide ISA 51 (REF. ${ }^{182}$ ). These polymeric microspheres were designed to be fully resorbed in vivo with lower antibody serum levels, providing a long-lasting immunotherapy delivery system with a decreased risk of adverse systemic effects ${ }^{182}$.

\section{Implantable biomaterials to programme dendritic cells in situ.}

Dendritic cell-based vaccines seek to improve the immune response to cancer by isolating and activating dendritic cells ex vivo and reintroducing them into the patient so they can traffic to lymph nodes and present antigens to naive $\mathrm{T}$ cells to subsequently expand and elicit antitumour responses. However, these vaccines require complex modifications of cells in vitro, and most injected cells die upon transplantation ${ }^{184}$. To overcome this, implantable biomaterials, which provide a physical structure to attract and programme dendritic cells for immunotherapy in $\operatorname{situ}^{36,185}$ (FIG. 4), have been used for cancer therapy ${ }^{144}$. In these systems, polymeric scaffolds serve as the drug delivery device, controlling the delivery of bioactive molecules in space and time to recruit dendritic cells and induce their proliferation ${ }^{36,186}$. Tumour antigens can also be immobilized on these matrices, enabling them to serve as antigen-presenting structures where dendritic cells are recruited, activated, loaded with antigen and released ${ }^{36,186}$.

In one example of an implantable biomaterial, porous poly(lactide-co-glycolide) (PLG) scaffolds were encapsulated with GM-CSF to stimulate dendritic cell recruitment and proliferation. Upon implantation in mice, these scaffolds recruited approximately the same number of dendritic cells as are typically administered using ex vivo based protocols ${ }^{36,187}$. Unlike a conventional bolus vaccination, the implantable scaffolds created a physical environment in vivo that secreted and presented antigens and stimulatory signals to dendritic cells over the course of 2 weeks ${ }^{34}$. Encapsulation of bioactive molecules (GM-CSF or CpG oligodeoxynucleotides (CpG-ODNs)) in combination with tumour cell lysate antigen immobilization on the scaffold generated specific and protective antitumour immunity upon implantation in vivo, and this induced complete regression of tumours in $\sim 47 \%$ of mice in a preclinical melanoma model ${ }^{36,186}$.

Immunostimulatory agents can also be incorporated into these systems, and their release can be tightly controlled. Inflammatory cytokines such as CC-chemokine ligand 20 (CCL20) or FMS-related tyrosine kinase 3 ligand (FLT3L) have been used in scaffolds to alter dendritic cell subset recruitment and activation, which generated antitumour responses in a mouse model of melanoma ${ }^{188}$. Furthermore, numerous sources of tumour lysate, including murine lung carcinoma and rat glioma, have been incorporated into scaffolds as antigens, expanding the therapeutic activity of immunotherapies in model organisms ${ }^{189,190}$. A human version of this vaccine, termed WDVAX (ClinicalTrials.gov identifier: NCT01753089), is currently 
being evaluated in a phase I clinical trial for stage IV melanoma and has been licensed to Novartis for commercial use ${ }^{191}$. However, the use of tumour cell lysates could increase the complexity of clinical translation. Moving forward, platforms should be engineered to incorporate specified antigens or synthetic neoantigens to create personalized vaccines ${ }^{192}$.

\section{Injectable scaffolds for immunotherapy.}

The scaffold-based delivery system requires an invasive surgical procedure for implantation, which presents a logistical challenge. In addition to implantable scaffolds, materials including alginate hydrogels, gelatin and mesoporous silica microrods are being designed to create local immunogenic environments that recruit, activate and release immune cells in vivo without the need for surgical implantation ${ }^{185,193-196}$. These materials are both highly deformable and self-organizing and thus can be administered via injection.

In one example of this, injectable high-aspect-ratio mesoporous silica rods were designed to spontaneously self-assemble in vivo to form macroporous structures for immune cells ${ }^{185,196}$ (FIG. 4). Mesoporous silica has been utilized extensively for controlled drug delivery owing to its high pore volume, large surface area, and biocompatibility ${ }^{197,198}$. Upon injection in mice, silica rods nonspecifically assembled into porous structures that were large enough to host immune cells and also released embedded GM-CSF, CpG-ODNs and tumour antigens ${ }^{185}$. Compared with bolus controls, the silica rod-based vaccine increased the number of cytotoxic $\mathrm{T}$ cells and the levels of serum antibodies that result from helper $\mathrm{T}$ cell activation and also extended survival in a mouse model of lymphoma ${ }^{185}$. Nanoparticles have also been modified with the cationic polymer polyethyleneimine (PEI) ${ }^{197,199}$, which can stimulate pro-inflammatory cytokine production ${ }^{200}$, as a means to increase the immunogenicity of neoantigens that target heterogeneous tumour clones ${ }^{196}$. Although this strategy avoids the risks associated with surgical implantation, the biodegradation and safety of injected silica rods and PEI will need to be investigated further in future studies.

\section{Injectable hydrogels for combination immunotherapy-chemotherapy.}

As a biodegradable alternative to silica, injectable in situ forming hydrogels have been designed to locally deliver combinations of immunotherapies and chemotherapies ${ }^{201}$. Combination approaches could be particularly useful for treating patients with lowimmunogenicity tumours that respond poorly to checkpoint inhibitors or patients who have immune-related side effects ${ }^{201}$. In one study, injectable poly(vinyl alcohol) (PVA) hydrogel networks were designed to be responsive to reactive oxygen species, which are present at high levels in the tumour microenvironment ${ }^{202}$. Upon injection in a low-immunogenicity murine model of breast cancer, the hydrogel degraded and first released the chemotherapeutic gemcitabine to kill cancer cells and promote an immunogenic tumour phenotype and then released an anti-PD-L1 antibody to stimulate antitumour immunity ${ }^{201}$. Local injection of hydrogels also inhibited post-surgical tumour recurrence in a murine model of melanoma, extending survival compared with local or systemic injections of free gemcitabine and an anti-PD-L1 antibody ${ }^{201}$. Because injectable hydrogels can locally deliver both chemotherapy drugs and immunotherapies such as checkpoint inhibitors, we anticipate that this strategy can improve the therapeutic outcome in cancers with low immunogenicity. Furthermore, this technique may avoid the toxic side effects associated 
with systemically administered checkpoint inhibitors or chemotherapies. In the future, these injectable hydrogels could be further engineered to enable high-precision control over the release kinetics of the loaded therapies for sustained treatment regimens.

\section{Transdermal delivery.}

Although systemically administered checkpoint inhibitors targeting CTLA4 or PD-1 have been approved for the treatment of melanoma, a substantial proportion of patients are not responsive to treatment (for example, the objective response rate to the anti-PD-1 mAb nivolumab in metastatic melanoma is $\sim 40 \%)^{203}$. Minimally invasive transdermal delivery systems have been designed to enable sustained release of anti-PD-1 mAbs in a controlled manner directly at the disease site, thereby minimizing the required dose ${ }^{38,143,204}$ (FIG. 4). These delivery systems consist of a degradable microneedle patch ${ }^{205}$, which can painlessly penetrate skin to reach the immune cell-rich epidermis to deliver immunotherapeutics ${ }^{38,143}$. Microneedles typically consist of a biodegradable polymer, such as hyaluronic acid, and are loaded with $\mathrm{pH}$-sensitive nanoparticles that contain anti-PD-1 (REF. ${ }^{143}$ ). In the mildly acidic tumour microenvironment, $\mathrm{pH}$-sensitive nanoparticles release anti-PD-1 to locally activate the immune system to attack cancer cells. In a mouse model of melanoma, a single administration of the microneedle-based patch induced a robust immune response compared with non-pH-responsive microneedles or intratumoural injection of free anti-PD-1 antibodies, achieving $40 \%$ survival after 40 days, whereas other treatment groups died after 30 days $^{143}$.

The microneedle delivery system is highly modular, as nanoparticles within the microneedles can be integrated with other immune-modulating drugs such as 1-methyl-DLtryptophan (1-MT), an inhibitor of the immunosuppressive enzyme indoleamine 2,3dioxygenase (IDO) ${ }^{38}$. Combined transdermal delivery of anti-PD-1 and 1-MT via $\mathrm{pH}$ sensitive microneedles resulted in $70 \%$ survival after 40 days in a murine model of melanoma, which was a substantial improvement over control groups ${ }^{38}$. Microneedle patches have also been integrated with the natural biological pigment melanin to improve immunotherapy delivery ${ }^{204}$. In this study, microneedle patches were loaded with whole tumour cell lysate and melanin. When exposed to near-infrared light, the melanin generates heat, which causes the local release of inflammatory cytokines, adjuvants and other danger signals from endogenous tissue to attract and activate immune cells ${ }^{204}$. Microneedles loaded with melanin and tumour lysate promoted tumour antigen uptake by dendritic cells in a mouse model of melanoma and induced complete tumour rejection in $87 \%$ of treated mice exposed to near-infrared light, whereas microneedle-treated mice without near-infrared exposure died after 35 days ${ }^{204}$.

Collectively, microneedle-based transdermal delivery systems offer a highly modular approach for local immunotherapy, exploiting both biological and remotely triggered stimuli for controlled drug release. Evaluation of the bioavailability of therapeutics within the patch, as well as the biocompatibility of the delivery system, will require further studies to assess clinical translatability. 


\section{T cell therapy delivery technologies}

\section{Surface-conjugated nanoparticles for cell engineering.}

A major limitation of adoptive $\mathrm{T}$ cell therapies is that the viability and function of the transplanted cells rapidly decline after administration. Such cell-based therapies therefore require concurrent administration of adjuvant drugs to maximize the efficacy and performance of the cells ${ }^{206}$. However, these drugs need to be administered systemically at high dosages, leading to numerous toxic side effects ${ }^{74}$. To overcome these obstacles, delivery technologies consisting of nanoparticles, scaffolds or a combination of both are now being explored.

Adjuvant-loaded nanoparticles that are chemically conjugated to the surface of donor $\mathrm{T}$ cells as a means to stimulate transplanted cells and minimize the systemic side effects of adjuvants have been designed ${ }^{207}$ (FIG. 5a). In one example, liposomes and liposome-like synthetic particles that encapsulated adjuvants were stably functionalized to the surface of $\mathrm{T}$ cells via maleimide-based conjugation ${ }^{207}$. In a metastatic murine model of melanoma, nanoparticle-functionalized $\mathrm{T}$ cells that contained adjuvant substantially boosted $\mathrm{T}$ cell production compared with the systemic administration of the free adjuvant ${ }^{207}$. All mice treated with nanoparticle-functionalized T cells achieved complete tumour clearance, whereas treatment with non-functionalized $\mathrm{T}$ cells plus free adjuvant achieved only modest survival improvements over untreated mice ${ }^{207}$. This approach is highly modular and has been adapted to deliver a range of immune-stimulating drugs. In other studies, nanoparticlefunctionalized $\mathrm{T}$ cells have been utilized for synapse-directed delivery of immunomodulators to improve adoptive $\mathrm{T}$ cell therapy in a murine model of prostate cancer ${ }^{208}$, as well as to improve the delivery of chemotherapeutics with unfavourable pharmacokinetics to disseminated tumours in a mouse model of lymphoma ${ }^{209}$.

Immune-stimulating drug delivery systems conjugated directly to the surface of $\mathrm{T}$ cells can reduce the toxic side effects of systemic administration and simultaneously exploit the ability of $\mathrm{T}$ cells to migrate into tumours, which improves drug penetration at disease sites. One challenge is how quickly $\mathrm{T}$ cells can proliferate in vivo in large animal models and whether in vivo $\mathrm{T}$ cell proliferation is a more appropriate measurement than in vitro expansion. The liposomal and multila-mellar lipid nanoparticles used in these studies also have a short release profile and, thus, investigation into polymeric platforms that achieve long-term release of adjuvants could increase $\mathrm{T}$ cell proliferation in vivo.

\section{In situ T cell engineering via DNA nanocarriers.}

In an effort to overcome the elaborate procedures and high costs required to generate large numbers of adoptive $\mathrm{T}$ cells in vitro ${ }^{210}$, delivery technologies to engineer $\mathrm{T}$ cells in situ are now being developed ${ }^{211}$ (FIG. 5b). As an alternative to in vitro genetic engineering, a nanoparticle platform was designed to reprogramme $\mathrm{T}$ cells in the circulation with leukaemia-recognizing CAR genes ${ }^{211}$. The platform was designed to target and enter $\mathrm{T}$ cells in the bloodstream of the mouse and then deliver CAR genes into the T cell nucleus ${ }^{211}$. Poly ( $\beta$-amino ester) (PBAE)-based nanoparticles were utilized to deliver DNA cargo into the nucleus of $\mathrm{T}$ cells ${ }^{212}$ and were further functionalized with peptides containing 
microtubule-associated sequences and nuclear localization signals to facilitate nuclear import of CAR-encoding DNA ${ }^{211}$. Nanoparticles were coated with polyglutamic acid to shield the positive charge of the PBAE and functionalized with antibody fragments targeting $\mathrm{CD} 3$ on $\mathrm{T}$ cells to enable receptor mediated endocytosis ${ }^{211}$. Nanoparticles administered systemically to mice bound primarily to circulating $\mathrm{T}$ cells, with minimal binding to other circulating cells in blood ${ }^{211}$. In a mouse model of B cell lymphoblastic leukaemia, nanoparticles administered systemically achieved sufficient CAR expression in $\mathrm{T}$ cells to eradicate tumours in seven out of ten mice, whereas the remaining three mice survived for an average of 58 days longer than controls ${ }^{211}$. Importantly, the efficacy of this platform was comparable to conventional adoptive $\mathrm{T}$ cell therapy, as no substantial differences in animal survival were observed between adoptive $\mathrm{T}$ cell therapy and the nanoparticle-based approach $^{211}$.

Collectively, engineering $\mathrm{T}$ cells in situ using nanoparticles could provide a practical and low-cost means of engineering CAR T cells directly in the patient to treat cancer. However, ex vivo engineering of CAR T cells avoids the potential off-target effects that gene therapies have when administered systemically, and the potential toxic side effects of introducing CAR genes into nontarget cells remains unclear. Future studies will need to address whether the cost-saving benefits of programming CAR T cells in vivo will outweigh the potential safety concerns regarding unintentional gene transfer.

\section{Biomaterial-based implants for local adoptive T cell delivery.}

Beyond systemic administration routes, biomaterials-based strategies have also been explored to locally deliver adoptive $\mathrm{T}$ cells to solid tumours 37,213 . Although adoptive $\mathrm{T}$ cell therapies have yielded promising results for several types of cancers, including melanoma and haematological malignancies ${ }^{214-216}$, successful targeting of $\mathrm{T}$ cells to most solid cancers remains challenging ${ }^{13}$. These therapies are impaired, in part, by the inefficient migration of $\mathrm{T}$ cells into tumours and a lack of $\mathrm{T}$ cell expansion in the immunosuppressive tumour microenvironment ${ }^{217-219}$. Therefore, technologies that locally deliver $\mathrm{T}$ cells to the tumour microenvironment and increase their proliferation could provide a means to treat inoperable solid tumours via immunotherapy.

Polymeric scaffolds have recently been investigated for the local delivery of $\mathrm{T}$ cells to the tumour microenvironment ${ }^{37,213}$. In addition to localizing $\mathrm{T}$ cells at or near tumour sites, polymeric scaffolds are advantageous because they can act as reservoirs from which propagating $\mathrm{T}$ cells are released as the material degrades ${ }^{37}$. Peptides that bind to $\mathrm{T}$ cell adhesion receptors can also be chemically conjugated to polymer scaffolds, thus mimicking the collagen fibres to which $\mathrm{T}$ cells normally bind, which enables their migration out of the scaffold and into tumours ${ }^{37}$. In addition to adhesion peptides, scaffolds can also be functionalized with various immune-stimulating drugs, such as adjuvants, as a means to enable both local T cell-mediated tumour destruction and systemic antitumour immunity ${ }^{213}$.

In a recent study, polymerized alginate scaffolds functionalized with a collagen-mimetic peptide were designed to deliver both $\mathrm{T}$ cells and silica microparticles to stimulate and promote the proliferation of $\mathrm{T}$ cells ${ }^{37}$. The silica microparticles embedded within the scaffold encapsulated a T cell-stimulating IL-15 superagonist, and they were coated with a 
lipid membrane that was functionalized with antibodies to promote receptor-mediated $\mathrm{T}$ cell proliferation ${ }^{37}$. In a murine model of breast cancer resection, local delivery of scaffolds to resection sites prevented tumour relapse entirely compared with systemically administered $\mathrm{T}$ cells, which yielded no improvement over untreated controls ${ }^{37}$. In an aggressive, immunosuppressive mouse model of ovarian cancer, local delivery of $\mathrm{T}$ cell implants eradicated six out of ten tumours and induced substantial regression in the others, whereas systemically or locally administered T cells had little curative effect ${ }^{37}$. In another study, T cell-loaded scaffolds were functionalized with STING agonists as a means to trigger systemic immunity, thereby stimulating immune responses to eliminate tumour cells in a murine model of pancreatic cancer that is not recognized by adoptively transferred $\mathrm{T}$ cells $^{213}$.

Overall, biomaterial-mediated local $\mathrm{T}$ cell delivery approaches could improve the efficiency of adoptive $\mathrm{T}$ cell therapies for treating inoperable solid tumours by overcoming local immunosuppressive barriers. Promoting the expansion of T cells within polymeric scaffolds removes the need to expand $\mathrm{T}$ cells in vitro for systemically administered therapies and minimizes the need for systemically administered conditioning regimens that are associated with toxic side effects. The usefulness of these therapies depends on how quickly $\mathrm{T}$ cells can be generated in tumours in vivo using this approach relative to the time it takes to expand $\mathrm{T}$ cells ex vivo. Furthermore, it remains to be elucidated whether this approach, designed to locally target tumours, can eliminate distant metastases in advanced stages of cancer.

\section{Synthetic artificial antigen-presenting cells.}

Synthetic artificial antigen-presenting cells (aAPCs) are cell-like particles that have T cellstimulating molecules conjugated to their surface and therefore mimic $\mathrm{APCs}^{220}$. The resultant signal transduction activates T cells and triggers an antitumour response (FIG. 5c). Compared with cell-based approaches, aAPCs are simple to produce and can be stably stored and functionalized with a variety of antigens and surface ligands for tuneable immunotherapy. aAPCs have conventionally consisted of cellular scale $(2-10 \mu \mathrm{m})$ spherical particles predominantly comprising lipids, magnetic molecules or polymers ${ }^{220-222}$.

Although such aAPCs can activate $\mathrm{T}$ cells in vitro, the in vivo activation of $\mathrm{T}$ cells using this approach remains challenging because of the poor bioavailability and the large size of cellular scale aAPCs. To enable in vivo delivery, nanoscale aAPCs have recently been designed $^{221,222}$. In one example, biodegradable PLGA nanoparticles were fabricated using a film stretching technique to create nanoellipsoidal aAPCs, which had a surface area that was large enough to increase receptor binding for $\mathrm{T}$ cell activation but was still ideal in size for in vivo delivery 221,222 . These aAPCs were functionalized with an MHC class I immunoglobulin dimer to enable T cell recognition by APCs and provide antigen-specificity along with the co-stimulatory anti-CD28 signal that is required for T cell activation ${ }^{221}$. Compared with spherical nano-aAPCs, ellipsoidal nano-aAPCs experienced reduced macrophage uptake, improved $\mathrm{T}$ cell stimulation and had superior pharmacokinetics in vivo $^{221}$. Interestingly, a spherical microparticle version of this particle has also been developed to treat melanoma: PLGA-based aAPCs functionalized with an MHC immunoglobulin $\mathrm{G}(\operatorname{IgG})$ dimer and an anti-CD28 antibody have been delivered in 
combination with an anti-PD-1 checkpoint inhibitor ${ }^{222}$. Collectively, synthetic aAPC delivery systems offer a potential alternative to conventional adoptive $\mathrm{T}$ cell therapy by simultaneously presenting multiple signals on the surface of synthetic particles to activate $\mathrm{T}$ cells in vivo. Future iterations of these systems should assess the role of other physicochemical properties, such as particle rigidity and lipid membrane fluidity, to further optimize aAPC-T cell interactions.

\section{Clinical translation}

A range of approaches to overcome biological barriers that hinder the broad implementation of cancer immunotherapy have been discussed in this article. These technologies present several challenges and opportunities for clinical translation. First, the choice of animal models used to evaluate these platforms greatly affects the translatability from mice to humans. For example, subcutaneous implantation of immortalized cell lines, although fairly simple to implement, is not as physiologically relevant as other tumour models such as patient-derived xenograft (PDX) models and GEM models, which more closely replicate human disease ${ }^{223}$. However, the PDX model still requires immunocompromised animals, making it challenging to translate immunotherapy results from these models to humans with intact immune systems ${ }^{223}$. Alternatively, in GEM models, immunocompetent mice are engineered to spontaneously develop diseases that are directly relevant to human disease ${ }^{223}$. The GEMs can be used to evaluate immunotherapies, but experiments can be challenging to design and control owing to the spontaneity of disease formation ${ }^{223}$. For more control over disease progression, tumours from GEMs can be harvested and implanted into healthy immunocompetent mice to form syngeneic GEM models, which are strong candidates for investigating metastatic disease from a single tumour source but are not as relevant to human disease as true GEM models because the tumours are implanted ${ }^{223}$. It is also important to note that the immune system in immunocompetent mice still has several key differences to that of humans. For example, healthy mice have a substantially higher percentage of lymphocytes than humans do, and mouse and human $\mathrm{T}$ cells have different expression levels and functions of cytokine receptors and co-stimulatory molecules ${ }^{224}$. The critical advantages and disadvantages of each mouse model, and the key differences in immune activity between animal models and humans, underscore the importance of evaluating therapies in various animal models as part of the FDA approval process ${ }^{225,226}$.

Choosing the correct preclinical model is critical, as is designing delivery technologies that can feasibly be translated to patients. Some essential design criteria for clinical translation include stability of the therapy, scalability, and production cost and complexity 227. Furthermore, the choice of materials affects the timeline for clinical translation. For example, developing systems that use FDA-approved materials are likely to get into the clinic faster than more complex, unapproved materials. This is particularly useful for lipidbased and polymer-based materials, as there are several already approved by the FDA that can be engineered as platforms for drug delivery 228,229 . We previously discussed an interesting application that uses FDA-approved lipids to deliver mRNA to dendritic cells ${ }^{156}$. This technology is currently being evaluated in clinical trials of melanoma (NCT02410733). A challenge in this strategy, however, is that no mRNA-based drug is currently approved by the FDA, so this therapy may take longer to reach the clinic. Excitingly, Alnylam 
Pharmaceuticals recently acquired FDA approval for their lipid-siRNA complex ${ }^{135}$, which may set a precedence for other RNA delivery platforms for cancer therapy. Additionally, an injectable scaffold for delivering a cancer vaccine, termed WDVAX, has been licensed to Novartis and is being evaluated in clinical trials (NCT01753089) ${ }^{191}$. Importantly, these scaffolds comprise proteins loaded into PLGA, which is already approved by the FDA for a variety of applications ${ }^{230}$. The recent efforts of Novartis and Alnylam, along with many other pharmaceutical and biotechnology companies, are setting the foundations for the delivery of new immunotherapies that require novel delivery technologies for successful cancer treatment.

\section{Conclusions and future directions}

Major challenges remain before immunotherapeutics can be administered to a broad range of patients; innovation in drug delivery technologies could address many of these. Although immunotherapy has been extensively studied and broadly implemented in haematological cancers and melanoma, targeting solid tumours with currently available immunotherapies has not been achieved. The delivery of immune cells to solid tumours could be improved through a better understanding of immune cell transport into solid tissues. For example, CAR T cells have been shown to penetrate the blood-brain barrier ${ }^{128,231}$. It is speculated that this is an effect of increased permeability of the blood-brain barrier in patients with certain diseases, although the precise mechanism by which this occurs remains under investigation ${ }^{231}$. New strategies to engineer $\mathrm{T}$ cells to express CARs, such as the use of CRISPR-Cas9 for multiplexed genome editing ${ }^{232,233}$, could further improve our fundamental understanding of $\mathrm{T}$ cell delivery to target organs.

Targeting immune cells to solid tumours by cell transfer or vaccination is difficult because of the potentially immunosuppressive tumour microenvironment, high interstitial fluid pressure, compressed vasculature and dense fibrotic tissue surrounding solid tumours that hinders $\mathrm{T}$ cell infiltration. Future approaches that target both the immune system and the tumour microenvironment could lead to more effective immunotherapies. For example, the mechanism by which angiotensin inhibitors - which reduce extracellular matrix stiffening and increase overall survival of patients with pancreatic cancer - alter the tumour microenvironment was evaluated in patients with nonmetastatic pancreatic cancer ${ }^{234}$. Specifically, treatment with angiotensin inhibitors normalized the extracellular matrix, reduced expression of genes involved in pancreatic cancer, progression and increased expression of genes involved in T cell and APC activity, indicating that angiotensin inhibitors may stimulate the immune system to recognize pancreatic cancer ${ }^{234}$. Given that the angiotensin inhibitor losartan is being used in patients with pancreatic cancer in a phase II clinical trial (NCT01821729) ${ }^{235}$ and has been shown to improve therapeutic delivery to a range of solid tumour types ${ }^{236}$, angiotensin inhibitors could play a future role in priming the tumour microenvironment for immunotherapy in a range of cancers. Other undiscovered drug targets in the tumour microenvironment could spur novel delivery strategies to target solid tumours.

Beyond the microenvironment, the innate ability of other blood cells in circulation to respond to pathological conditions can also be exploited to deliver immunotherapy. 
Macrophages, which readily invade and accumulate within solid tissues in numerous inflammatory diseases and solid tumours, could overcome the physical barriers faced by $\mathrm{T}$ cells $^{237,238}$. For example, macrophages were recently engineered to directly attack tumour cells in vivo by inhibiting SHP substrate 1 (also known as SIRPa), which prevents macrophages from attacking CD47-expressing tumour cells, using blocking antibodies ${ }^{237}$. In a mouse model of lung cancer, systemically administered SIRPa-inhibited macrophages specifically accumulated within tumours and induced regression for 1-2 weeks with minimal toxicity ${ }^{237}$. SIRPa-inhibited macrophages differentiate into tumour-associated macrophages within a week of administration and, thus, further research investigating the effects of repeated administration on tumour regression and toxicity is required ${ }^{237}$.

Future work should also investigate new delivery technologies to expand and engineer cell therapies ex vivo. Microfluidics-based technologies have recently been developed to improve and speed up the ex vivo intracellular delivery of macromolecules to immune cells $^{239,240}$. Such vector-free delivery systems consist of cells that undergo rapid mechanical deformation as they pass through a constriction point within a microfluidic channel ${ }^{241}$. This deformation transiently disrupts the membrane of immune cells, enabling uptake of macromolecular cargo present in the buffer. This technology has been used to rapidly $(\sim 1$ million cells per second) deliver a range of nucleic acids and macromolecules to immune cells, including T cells, B cells, dendritic cells and macrophages ${ }^{239,240}$. Such a delivery strategy could overcome the challenges faced by electroporation-based and vector-based delivery of nucleic acids to immune cells ex vivo ${ }^{242}$. Although this technology is still in preclinical development, a spinout company based on this technology, SQZ Biotech (see Related links), has partnered with Roche to rapidly engineer APCs for immunotherapy.

In addition to improving delivery, biomaterials should also be designed to improve the ex vivo expansion of $\mathrm{T}$ cells ${ }^{243-245}$, which currently leads to suboptimal $\mathrm{T}$ cell expansion rates and products ${ }^{246}$. Utilizing similar scaffolds for programming dendritic cells in situ ${ }^{185}$, recent work has investigated mesoporous silica microrods coated with a fluid lipid bilayer, antiCD3 and anti-CD28 antibodies, and IL-2 to create an APC-mimetic scaffold for T cell expansion $^{246}$. By more accurately reproducing how these signals are presented by APCs in vivo, these scaffolds promoted twofold to tenfold greater polyclonal expansion of primary mouse and human $\mathrm{T}$ cells than the commercial expansion beads that are typically used, with similar in vivo efficacy in a mouse model of lymphoma ${ }^{246}$. Improved expansion and functionality of $\mathrm{T}$ cells using biomaterials can potentially improve $\mathrm{T}$ cell delivery in future studies via increased migration into target tissues with reduced off-target effects.

Future work could implement externally or internally triggered drug delivery systems, in which therapeutic payloads or engineered immune cells can be triggered to stimulate an antitumour response on demand at target tissue sites, which would reduce off-tissue effects. Indeed, early work in this area is now exploring the use of methods that are triggered mechanically, or by $\mathrm{pH}$, light or ultrasound, for remotely controlled immunotherapy ${ }^{33-35}$. Examples that exploit the use of clinically approved materials and modalities, such as microbubbles and ultrasound, respectively, could have a somewhat simple path to clinical translation $^{35}$. Furthermore, given that several biomaterials and drug delivery technologies activate immunostimulatory pathways in the absence of other immune signals ${ }^{247,248}$, future 
fundamental investigations into biomaterial-immune cell interactions will be needed to design new technologies for delivery and to actively direct immune responses. Several unanswered questions remain regarding how the physiochemical properties (size, shape, charge, hydrophobicity and chemical functionality) of biomaterials influence the activation of specific immune pathways and, on a larger scale, how these interactions alter the function of important tissues involved in immunity. Future investigation into these areas could enable new strategies to leverage the immunogenicity of biomaterials in cancer immunotherapies.

Although the field of cancer immunotherapy as a whole is advancing at a rapid pace, the design of delivery technologies for this field is still in its nascent stages. In this article, we described specific examples of novel delivery systems that could improve immunotherapy because of the engineered properties of the platforms themselves, including those for targeted and/or localized delivery, controlled release, increased stability and vaccination. Not only do many of the delivery platforms described in this Review provide a means to improve the delivery of immunotherapy, many examples also provide a means to overcome the innate heterogeneity of cancer, the importance of which we anticipate will become increasingly recognized in the coming years. For example, many systems, including nanoparticles, scaffolds, hydrogels and cells, can be loaded with multiple therapeutic agents that are chosen on the basis of targets identified in patient biopsy samples. This personalized therapeutic approach would enable more comprehensive and potentially curative approaches to cancer immunotherapy. Thus, the lines of drug delivery research described here, at both the fundamental and applied levels, will prove essential in contributing to future innovations for broadly implementing cancer immunotherapy.

\section{Acknowledgements}

M.J.M. is supported by a Burroughs Wellcome Fund Career Award at the Scientific Interface, a US National Institutes of Health (NIH) Director's New Innovator Award (DP2 TR002776) and a grant from the American Cancer Society (129784-IRG-16-188-38-IRG). R.S.R. is supported by an NIH T32 multidisciplinary training grant. The authors' work is supported in part by Cancer Center Support (core) Grant P30-CA14051 from the US National Cancer Institute and a grant from the Koch Institute's Marble Centre for Cancer Nanomedicine (to R.L.).

\section{References}

1. Thomas B, Coates D, Tzeng V, Baehner L \& Boxer A Treatment of hairy cell leukemia with recombinant alpha-interferon. Blood 68, 493-497 (1986). [PubMed: 3730612]

2. Ahmed S \& Rai K Interferon in the treatment of hairy-cell leukemia. Best Pract. Res. Clin. Haematol. 16, 69-81 (2003). [PubMed: 12670466]

3. Rosenberg SA IL-2: the first effective immunotherapy for human cancer. J. Immunol. 192, 54515458 (2014). [PubMed: 24907378]

4. Lee S \& Margolin K Cytokines in cancer immunotherapy. Cancers (Basel) 3, 3856-3893 (2011). [PubMed: 24213115]

5. Kirchner GI et al. Pharmacokinetics of recombinant human interleukin-2 in advanced renal cell carcinoma patients following subcutaneous application. Br. J. Clin. Pharmacol. 46, 5-10 (1998). [PubMed: 9690943]

6. Rosenberg SA et al. A progress report on the treatment of 157 patients with advanced cancer using lymphokine-activated killer cells and interleukin-2 or high-dose interleukin-2 alone. N. Engl. J. Med. 316, 889-897 (1987). [PubMed: 3493432] 
7. Alwan L et al. Comparison of acute toxicity and mortality after two different dosing regimens of high-dose interleukin-2 for patients with metastatic melanoma. Target. Oncol. 9, 63-71 (2014). [PubMed: 23609056]

8. Rosenberg SA, Yang JC \& Restifo NP Cancer immunotherapy: moving beyond current vaccines. Nat. Med. 10, 909-915 (2004). [PubMed: 15340416]

9. Kantoff PW et al. Sipuleucel-T immunotherapy for castration-resistant prostate cancer. N. Engl. J. Med. 363, 411-422 (2010). [PubMed: 20818862]

10. Graff JN \& Chamberlain ED Sipuleucel-T in the treatment of prostate cancer: an evidence-based review of its place in therapy. Core Evid. 10, 1-10 (2015). [PubMed: 25565923]

11. Hodi FS et al. Improved survival with ipilimumab patients with metastatic melanoma. N. Engl. J. Med. 363, 711-723 (2010). [PubMed: 20525992]

12. Ribas A \& Wolchok JD Cancer immunotherapy using checkpoint blockade. Science 359, 1350 1355 (2018). [PubMed: 29567705]

13. Fesnak AD, June CH \& Levine BL Engineered T cells: the promise and challenges of cancer immunotherapy. Nat. Rev. Cancer 16, 566-581 (2016). [PubMed: 27550819]

14. Porter DL et al. Chimeric antigen receptor $\mathrm{T}$ cells persist and induce sustained remissions in relapsed refractory chronic lymphocytic leukemia. Sci. Transl Med. 7, 1-12 (2015).

15. June CH, O’Connor RS, Kawalekar OU, Ghassemi S \& Milone MC CAR T cell immunotherapy for human cancer. Science 359, 1361-1365 (2018). [PubMed: 29567707]

16. Grupp SA et al. Chimeric antigen receptor-modified T cells for acute lymphoid leukemia. N. Engl. J. Med. 368, 1509-1518 (2013). [PubMed: 23527958]

17. Couzin-Frankel J Cancer immunotherapy. Science 342, 1432-1433 (2013). [PubMed: 24357284]

18. Maleki Vareki S, Garrigós C \& Duran I Biomarkers of response to PD-1/PD-L1 inhibition. Crit. Rev. Oncol. Hematol. 116, 116-124 (2017). [PubMed: 28693793]

19. Hay KA et al. Kinetics and biomarkers of severe cytokine release syndrome after CD19 chimeric antigen receptor-modified T cell therapy. Blood 130, 2295-2306 (2017). [PubMed: 28924019]

20. Schmidt C The benefits of immunotherapy combinations. Nature 552, S67-S69 (2018).

21. Riley RS \& Day ES Gold nanoparticle-mediated photothermal therapy: applications and opportunities for multimodal cancer treatment. Wiley Interdiscip. Rev. Nanomed. Nanobiotechnol. 9, e1449 (2017).

22. Menon S, Shin S \& Dy G Advances in cancer immunotherapy in solid tumors. Cancers (Basel). 8, (1-21 (2016).

23. Williams AD et al. Immunotherapy for breast cancer: current and future strategies. Curr. Surg. Rep. 5, 31 (2017). [PubMed: 29657904]

24. Brown CE et al. Regression of glioblastoma after chimeric antigen receptor T-cell therapy. N. Engl. J. Med. 375, 2561-2569 (2016). [PubMed: 28029927]

25. Milling L, Zhang Y \& Irvine DJ Delivering safer immunotherapies for cancer. Adv. Drug Deliv. Rev. 114, 79-101 (2017). [PubMed: 28545888]

26. June CH, Warshauer JT \& Bluestone JA Is autoimmunity the Achilles' heel of cancer immunotherapy? Nat. Med. 23, 540-547 (2017). [PubMed: 28475571]

27. Wang C, Ye Y, Hu Q, Bellotti A \& Gu Z Tailoring biomaterials for cancer immunotherapy: emerging trends and future outlook. Adv. Mater. 29, 1-24 (2017).

28. Miller AD Lipid-based nanoparticles in cancer diagnosis and therapy. J. Drug. Deliv. 2013, 1-9 (2013).

29. Liechty WB, Kryscio DR, Slaughter BV \& Peppas NA Polymers for drug delivery systems. Annu. Rev. Chem. Biomol. Eng. 1, 149-173 (2010). [PubMed: 22432577]

30. Moon JJ, Huang B \& Irvine DJ Engineering nano- and microparticles to tune immunity. Adv. Mater. 24, 3724-3746 (2012). [PubMed: 22641380]

31. Toy R \& Roy K Engineering nanoparticles to overcome barriers to immunotherapy. Bioeng. Transl Med. 1, 47-62 (2016). [PubMed: 29313006]

32. Shao K et al. Nanoparticle-based immunotherapy for cancer. ACS Nano 9, 16-30 (2015).

[PubMed: 25469470] 
33. Wilson JT et al. pH-responsive nanoparticle vaccines for dual-delivery of antigens and immunostimulatory oligonucleotides. ACS Nano 7, 3912-3925 (2013). [PubMed: 23590591]

34. Zhang $\mathrm{C}$ et al. A light responsive nanoparticle-based delivery system using pheophorbide a graft polyethylenimine for dendritic cell-based cancer immunotherapy. Mol. Pharm. 14, 1760-1770 (2017). [PubMed: 28296410]

35. Pan Y et al. Mechanogenetics for the remote and noninvasive control of cancer immunotherapy. Proc. Natl Acad. Sci. USA 115, 992-997 (2018). [PubMed: 29343642]

36. Ali OA, Huebsch N, Cao L, Dranoff G \& Mooney DJ Infection-mimicking materials to program dendritic cells in situ. Nat. Mater. 8, 151-158 (2009). [PubMed: 19136947] In this paper, implantable polymeric scaffolds were designed to release cytokines to recruit host dendritic cells — as well as present cancer antigens and danger signals to activate those cells — as a means to generate specific and protective antitumour immunity.

37. Stephan SB et al. Biopolymer implants enhance the efficacy of adoptive T cell therapy. Nat. Biotechnol. 33, 97-101 (2015). [PubMed: 25503382] In this paper, polymeric scaffolds coated with collagen-mimetic peptides were used to bind and deliver antigen-specific $\mathrm{T}$ cells locally within the tumour microenvironment, demonstrating that these biomaterials have the potential to maximize the potency of immunotherapy for solid tumour applications.

38. Ye Y et al. Synergistic transcutaneous immunotherapy enhances antitumor immune responses through delivery of checkpoint inhibitors. ACS Nano 10, 8956-8963 (2016). [PubMed: 27599066]

39. Krishnamurthy A \& Jimeno A Bispecific antibodies for cancer therapy: a review. Pharmacol. Ther. 185, 122-134 (2018). [PubMed: 29269044]

40. Lawler S, Speranza M, Cho C \& Chiocca A Oncolytic viruses in cancer treatment. JAMA Oncol. 3, 841-849 (2017). [PubMed: 27441411]

41. Pardoll DM The blockade of immune checkpoints in cancer immunotherapy. Nat. Rev. Cancer 12, 252-264 (2012). [PubMed: 22437870]

42. Webb ES et al. Immune checkpoint inhibitors in cancer therapy. J. Biomed. Res. 32, 317-326 (2017).

43. Granier $\mathrm{C}$ et al. Mechanisms of action and rationale for the use of checkpoint inhibitors in cancer. ESMO Open 2, e000213 (2017). [PubMed: 28761757]

44. Alsaab HO et al. PD-1 and PD-L1 checkpoint signaling inhibition for cancer immunotherapy: mechanism, combinations, and clinical outcome. Front. Pharmacol. 8, 1-15 (2017). [PubMed: 28149278]

45. Munn DH \& Bronte V Immune suppressive mechanisms in the tumor microenvironment. Curr. Opin. Immunol. 39, 1-6 (2016). [PubMed: 26609943]

46. Blank C et al. Blockade of PD-L1 (B7-H1) augments human tumor-specific T cell responses in vitro. Int. J. Cancer 119, 317-327 (2006). [PubMed: 16482562]

47. Arce Vargas F et al. Fc effector function contributes to the activity of human anti-CTLA-4 antibodies. Cancer Cell 33, 649-663 (2018). [PubMed: 29576375]

48. Du X et al. A reappraisal of CTLA-4 checkpoint blockade in cancer immunotherapy. Cell Res. 28, 416-432 (2018). [PubMed: 29472691]

49. Simpson TR et al. Fc-dependent depletion of tumor-infiltrating regulatory T cells co-defines the efficacy of anti-CTLA-4 therapy against melanoma. J. Exp. Med. 210, 1695-1710 (2013). [PubMed: 23897981]

50. Ellis P, Vella E \& Ung Y Immune checkpoint inhibitors for patients with advanced non-small-cell lung cancer: a systematic review. Clin. Lung Cancer 18, 444-459 (2017). [PubMed: 28416123]

51. Friedman C, Proverbs-Singh T \& Powtow M Treatment of the immune-related adverse effects of immune checkpoint inhibitors: a review. JAMA Oncol. 2, 1346-1353 (2016). [PubMed: 27367787]

52. Naidoo J et al. Pneumonitis in patients treated with anti-programmed death-1/programmed death ligand 1 therapy. J. Clin. Oncol. 35, 709-717 (2017). [PubMed: 27646942]

53. Byun DJ, Wolchok JD, Rosenberg LM \& Girotra M Cancer immunotherapy-immune checkpoint blockade and associated endocrinopathies. Nat. Rev. Endocrinol. 13, 195-207 (2017). [PubMed: 28106152] 
54. Restifo NP, Smyth MJ \& Snyder A Acquired resistance to immunotherapy and future challenges. Nat. Rev. Cancer 16, 121-126 (2016). [PubMed: 26822578]

55. Garg AD, Coulie PG, Van den Eynde BJ \& Agostinis P Integrating next-generation dendritic cell vaccines into the current cancer immunotherapy landscape. Trends Immunol. 38, 577-593 (2017). [PubMed: 28610825]

56. Dillman RO Is there a role for therapeutic cancer vaccines in the age of checkpoint inhibitors? Hum. Vaccin. Immunother. 13, 528-532 (2017). [PubMed: 27808593]

57. Joyce J \& Fearon D T cell exclusion, immune privilege, and the tumor microenvironment. Science 348, 74-80 (2015). [PubMed: 25838376]

58. Katze MG, He Y \& Gale M Viruses and interferon: a fight for supremacy. Nat. Rev. Immunol. 2, 675-687 (2002). [PubMed: 12209136]

59. Sun $\mathrm{T}$ et al. Inhibition of tumor angiogenesis by interferon- $\gamma$ by suppression of tumor-associated macrophage differentiation. Oncol. Res. 21, 227-235 (2014). [PubMed: 24854099]

60. He T, Tang C, Xu S, Moyana T \& Xiang J Interferon gamma stimulates cellular maturation of dendritic cell line DC2.4 leading to induction of efficient cytotoxic T cell responses and antitumor immunity. Cell. Mol. Immunol. 4, 105-111 (2007). [PubMed: 17484804]

61. Müller L, Aigner P \& Stoiber D Type I interferons and natural killer cell regulation in cancer. Front. Immunol. 8, 1-11 (2017). [PubMed: 28149297]

62. Enomoto $\mathrm{H}$ et al. The in vivo antitumor effects of type I-interferon against hepatocellular carcinoma: the suppression of tumor cell growth and angiogenesis. Sci. Rep 7, 12189 (2017). [PubMed: 28939881]

63. Cox MA, Harrington LE \& Zajac AJ Cytokines and the inception of CD8 T cell responses. Trends Immunol. 32, 180-186 (2012).

64. Ben-Sasson SZ et al. IL-1 acts directly on CD4 T cells to enhance their antigen-driven expansion and differentiation. Proc. Natl Acad. Sci. USA 106, 7119-7124 (2009). [PubMed: 19359475]

65. Trinchieri G Interleukin-12 and the regulation of innate resistance and adaptive immunity. Nat. Rev. Immunol. 3, 133-146 (2003). [PubMed: 12563297]

66. Itoh K \& Hirohata S The role of IL-10 in human B cell activation, proliferation, and differentiation. J. Immunol. 154, 4341-4350 (1995). [PubMed: 7722292]

67. Yan W-L, Shen K-Y, Tien C-Y, Chen Y-A \& Liu S-J Recent progress in GM-CSF-based cancer immunotherapy. Immunotherapy 9, 347-360 (2017). [PubMed: 28303764]

68. Tanaka J, Mielcarek M \& Torok-Storb B Impaired induction of the CD28-responsive complex in granulocyte colony-stimulating factor mobilized CD4 T cells. Blood 91, 347-352 (1998). [PubMed: 9414304]

69. Mehta HM, Malandra M \& Corey SJ G-CSF and GM-CSF in neutropenia. J. Immunol. 195, 13411349 (2015). [PubMed: 26254266]

70. Uhl M et al. SD-208, a novel transforming growth factor beta receptor I kinase inhibitor, inhibits growth and invasiveness and enhances immunogenicity of murine and human glioma cells in vitro and in vivo. Cancer Res. 64, 7954-7961 (2004). [PubMed: 15520202]

71. Fu J et al. STING agonist formulated cancer vaccines can cure established tumors resistant to PD-1 blockade. Sci. Transl Med. 7, 283ra52 (2015).

72. Chi $\mathrm{H}$ et al. Anti-tumor activity of toll-like receptor 7 agonists. Front. Pharmacol. 8, 1-10 (2017). [PubMed: 28149278]

73. Perna SK et al. Interleukin-7 mediates selective expansion of tumor-redirected cytotoxic T lymphocytes (CTLs) without enhancement of regulatory T cell inhibition. Clin. Cancer Res. 20, 131-139 (2014). [PubMed: 24097874]

74. Berger SC et al. Safety and immunologic effects of IL-15 administration in nonhuman primates. Blood 114, 2417-2426 (2009). [PubMed: 19605850]

75. Hasan AN et al. Soluble and membrane-bound interleukin (IL)-15 Ra/IL-15 complexes mediate proliferation of high-avidity central memory CD8+T cells for adoptive immunotherapy of cancer and infections. Clin. Exp. Immunol. 186, 249-265 (2016). [PubMed: 27227483] 
76. Chapuis AG et al. Combined IL-21-primed polyclonal CTL plus CTLA4 blockade controls refractory metastatic melanoma in a patient. J. Exp. Med. 213, 1133-1139 (2016). [PubMed: 27242164]

77. Lim WA \& June CH The principles of engineering immune cells to treat cancer. Cell 168, 724-740 (2017). [PubMed: 28187291]

78. Scholler J et al. Decade-long safety and function of retroviral-modified chimeric antigen receptor $\mathrm{T}$ cells. Sci. Transl Med. 4, 132ra53 (2012).

79. Schuster SJ et al. Chimeric antigen receptor T cells in refractory B-cell lymphomas. N. Engl. J. Med. 377, 2545-2554 (2017). [PubMed: 29226764]

80. Levine BL, Miskin J, Wonnacott K \& Keir C Global manufacturing of CAR T cell therapy. Mol. Ther. Methods Clin. Dev. 4, 92-101 (2017). [PubMed: 28344995]

81. Davila ML \& Brentjens RJ CD19-Targeted CAR T cells as novel cancer immunotherapy for relapsed or refractory B cell acute lymphoblastic leukemia. Clin. Adv. Hematol. Oncol. 14, 802 808 (2016). [PubMed: 27930631]

82. Neelapu SS et al. Axicabtagene ciloleucel CAR T-cell therapy in refractory large B-cell lymphoma. N. Engl. J. Med. 377, 2531-2544 (2017). [PubMed: 29226797]

83. Maude SL et al. Tisagenlecleucel in children and young adults with B-cell lymphoblastic leukemia. N. Engl. J. Med. 378, 439-448 (2018). [PubMed: 29385370]

84. Frigault $\mathrm{MJ}$ et al. Identification of chimeric antigen receptors that mediate constitutive or inducible proliferation of T cells. Cancer Immunol. Res. 3, 356-367 (2015). [PubMed: 25600436]

85. O'Rourke DM et al. A single dose of peripherally infused EGFRvIII-directed CAR T cells mediates antigen loss and induces adaptive resistance in patients with recurrent glioblastoma. Sci. Transl Med. 9, 1-35 (2017).

86. Posey AD et al. Engineered CAR T cells targeting the cancer-associated Tn-glycoform of the membrane mucin MUC1 control adenocarcinoma. Immunity 44, 1444-1454 (2016). [PubMed: 27332733]

87. Bailey SR et al. Human CD26 $6^{\text {high }} \mathrm{T}$ cells elicit tumor immunity against multiple malignancies via enhanced migration and persistence. Nat. Commun. 8, 1961 (2017). [PubMed: 29213079]

88. Ruella $\mathrm{M}$ et al. Overcoming the immunosuppressive tumor microenvironment of Hodgkin lymphoma using chimeric antigen receptor T cells. Cancer Discov. 7, 1154-1167 (2017). [PubMed: 28576927]

89. Fitzgerald JC et al. Cytokine release syndrome after chimeric antigen receptor T cell therapy for acute lymphoblastic leukemia. Crit. Care. Med. 45, e124-e131 (2017). [PubMed: 27632680]

90. Van Den Berg JH et al. Case report of a fatal serious adverse event upon administration of T cells transduced with a MART-1-specific T cell receptor. Mol. Ther. 23, 1541-1550 (2015). [PubMed: 25896248]

91. Migliorini D et al. CAR T cell therapies in glioblastoma: a first look. Clin. Cancer Res. 24, 535540 (2018). [PubMed: 29158268]

92. Hege KM et al. Safety, tumor trafficking and immunogenicity of chimeric antigen receptor (CAR)T cells specific for TAG-72 in colorectal cancer. J. Immunother. Cancer 5, 1-14 (2017). [PubMed: 28105368]

93. Cohen M \& Reiter Y T-cell receptor-like antibodies: targeting the intracellular proteome therapeutic potential and clinical applications. Antibodies 2, 517-534 (2013).

94. Linnemann C et al. High-throughput identification of antigen-specific TCRs by TCR gene capture. Nat. Med. 19, 1534-1541 (2013). [PubMed: 24121928]

95. Cameron BJ et al. Identification of a Titin-derived HLA-A1 - presented peptide as a cross-reactive target for engineered MAGE A3 - directed T cells. Sci. Transl Med. 5, 197ra103 (2013).

96. Linette GP et al. Cardiovascular toxicity and titin cross-reactivity of af fi nity-enhanced T cells in myeloma and melanoma. Blood 122, 863-872 (2013). [PubMed: 23770775]

97. Peggs KS, Quezada SA \& Allison JP Cancer immunotherapy: co-stimulatory agonists and coinhibitory antagonists. Clin. Exp. Immunol. 157, 9-19 (2009). [PubMed: 19659765]

98. Croft M Co-stimulatory members of the TNFR family: keys to effective T cell immunity? Nat. Rev. Immunol. 3, 609-620 (2003). [PubMed: 12974476] 
99. Chester C, Sanmamed MF, Wang J \& Melero I Immunotherapy targeting 4-1BB: mechanistic rationale, clinical results, and future strategies. Blood 131, 49-57 (2018). [PubMed: 29118009]

100. Tolcher AW et al. Phase Ib study of utomilumab (PF-05082566), a 4-1BB/CD137 agonist, in combination with pembrolizumab (MK-3475) in patients with advanced solid tumors. Clin. Cancer Res. 23, 5349-5357 (2017). [PubMed: 28634283]

101. Segal NH et al. Results from an integrated safety analysis of urelumab, an agonist anti-CD137 monoclonal antibody. Clin. Cancer Res. 23, 1929-1936 (2017). [PubMed: 27756788]

102. Buchan SL, Rogel A \& Al-Shamkhani A The immunobiology of CD27 and OX40 and their potential as targets for cancer immunotherapy. Blood 131, 39-48 (2018). [PubMed: 29118006]

103. Zhang $\mathrm{P}$ et al. Agonistic anti-4-1BB antibody promotes the expansion of natural regulatory T cells while maintaining Foxp3 expression. Scand. J. Immunol 66, 435-440 (2007). [PubMed: 17850588]

104. Zhang Y, Li N, Suh H \& Irvine DJ Nanoparticle anchoring targets immune agonists to tumors enabling anti-cancer immunity without systemic toxicity. Nat. Commun. 9, 6 (2018). [PubMed: 29295974]

105. Guo C et al. Therapeutic cancer vaccines; past, present and future. Adv. Cancer Res. 119, 421475 (2013). [PubMed: 23870514]

106. Chiang C, Coukos $\mathrm{G} \&$ Kandalaft $\mathrm{L}$ Whole tumor antigen vaccines: where are we? Vaccines 3 , 344-372 (2015). [PubMed: 26343191]

107. Srivatsan $\mathrm{S}$ et al. Allogeneic tumor cell vaccines: the promise and limitations in clinical trials. Hum. Vaccin. Immunother. 10, 52-63 (2014). [PubMed: 24064957]

108. Mullard A The cancer vaccine resurgence. Nat. Rev. Drug Discov. 15, 663-665 (2016). [PubMed: 27681782]

109. Butterfield LH Dendritic cells in cancer immunotherapy clinical trials: are we making progress? Front. Immunol. 4, 1-7 (2013). [PubMed: 23355837]

110. Schreibelt $\mathrm{G}$ et al. Effective clinical responses in metastatic melanoma patients after vaccination with primary myeloid dendritic cells. Clin. Cancer Res. 22, 2155-2166 (2016). [PubMed: 26712687]

111. Pardi N, Hogan MJ, Porter FW \& Weissman D mRNA vaccines — a new era in vaccinology. Nat. Rev. Drug Discov. 17, 261-279 (2018). [PubMed: 29326426]

112. Yang B, Jeang J, Yang A, Wu TC \& Hung C-F DNA vaccine for cancer immunotherapy. Hum. Vaccin. Immunother. 10, 3153-3164 (2015).

113. McNamara MA, Nair SK \& Holl EK RNA-based vaccines in cancer immunotherapy. J. Immunol. Res. 2015, 794528 (2015). [PubMed: 26665011]

114. Liu MA DNA vaccines: an historical perspective and view to the future. Immunol. Rev. 239, 6284 (2011). [PubMed: 21198665]

115. Schlake T, Thess A, Fotin-Mleczek M \& Kallen KJ Developing mRNA-vaccine technologies. RNA Biol. 9, 1319-1330 (2012). [PubMed: 23064118]

116. Kauffman KJ, Webber MJ \& Anderson DG Materials for non-viral intracellular delivery of messenger RNA therapeutics. J. Control. Release 240, 227-234 (2016). [PubMed: 26718856]

117. Li L, Goedegebuure SP \& Gillanders WE Preclinical and clinical development of neoantigen vaccines. Ann. Oncol. 28, xii11-xii17 (2017). [PubMed: 29253113]

118. Lauss $\mathrm{M}$ et al. Mutational and putative neoantigen load predict clinical benefit of adoptive $\mathrm{T}$ cell therapy in melanoma. Nat. Commun. 8, 1738 (2017). [PubMed: 29170503]

119. Phua K, Nair S \& Leong K Messenger RNA (mRNA) nanoparticle tumour vaccination. Nanoscale 6, 7715-7729 (2014). [PubMed: 24904987]

120. Zhu G, Zhang F, Ni Q, Niu G \& Chen X Efficient nanovaccine delivery in cancer immunotherapy. ACS Nano 11, 2387-2392 (2017). [PubMed: 28277646]

121. Binnewies $\mathrm{M}$ et al. Understanding the tumor immune microenvironment (TIME) for effective therapy. Nat. Med. 24, 541-550 (2018). [PubMed: 29686425]

122. Song $\mathrm{W}$ et al. Synergistic and low adverse effect cancer immunotherapy by immunogenic chemotherapy and locally expressed PD-L1 trap. Nat. Commun. 9, 2237 (2018). [PubMed: 29884866] 
123. Wong $\mathrm{C}$ et al. Multistage nanoparticle delivery system for deep penetration into tumor tissue. Proc. Natl Acad. Sci. USA 108, 2426-2431 (2010).

124. Sahay $\mathrm{G}$ et al. Efficiency of siRNA delivery by lipid nanoparticles is limited by endocytic recycling. Nat. Biotechnol. 31, 653-658 (2013). [PubMed: 23792629]

125. Lopez-bertoni $\mathrm{H}$ et al. Bioreducible polymeric nanoparticles containing multiplexed cancer stem cell-regulating miRNAs inhibit glioblastoma growth and prolong survival. Nano Lett. 18, 40864094 (2018). [PubMed: 29927251]

126. Engel AL, Holt GE \& Lu H The pharmacokinectics of toll-like receptor agonists and the impact on the immune system. Expert Rev. Clin. Pharmacol. 4, 275-289 (2011). [PubMed: 21643519]

127. Whiteside TL, Demaria S, Rodriguez-Ruiz ME, Zarour HM \& Melero I Emerging opportunities and challenges in cancer immunotherapy. Clin. Cancer Res. 22, 1845-1855 (2016). [PubMed: 27084738]

128. Lyon JG, Mokarram N, Saxena T, Carroll SL \& Bellamkonda RV Engineering challenges for brain tumor immunotherapy. Adv. Drug Deliv. Rev. 114, 19-32 (2017). [PubMed: 28625831]

129. Sagiv-Barfi I et al. Eradication of spontaneous malignancy by local immunotherapy. Sci. Transl Med. 10, eaan4488 (2018). [PubMed: 29386357]

130. Hu B et al. Augmentation of antitumor immunity by human and mouse CAR T cells secreting IL-18. Cell Rep. 20, 3025-3033 (2017). [PubMed: 28954221]

131. Matsumura Y \& Maeda HA New concept for macromolecular therapeutics in cancer chemotherapy: mechanism of tumoritropic accumulation of proteins and the antitumor agent smancs. Cancer Res. 46, 6387-6392 (1986). [PubMed: 2946403]

132. Gerlowski LE \& Jain RK Microvascular permeability of normal and neoplastic tissues. Microvasc. Res. 31, 288-305 (1986). [PubMed: 2423854]

133. Xu X, Ho W, Zhang X, Bertrand N \& Farokhzad O Cancer nanomedicine: from targeted delivery to combination therapy. Trends Mol. Med. 21, 223-232 (2015). [PubMed: 25656384]

134. Bertrand N, Wu J, Xu X, Kamaly N \& Farokhzad OC Cancer nanotechnology: the impact of passive and active targeting in the era of modern cancer biology. Adv. Drug Deliv. Rev. 66, 2-25 (2014). [PubMed: 24270007]

135. Mitchell MJ, Jain RK \& Langer R Engineering and physical sciences in oncology: challenges and opportunities. Nat. Rev. Cancer 17, 659-675 (2017). [PubMed: 29026204]

136. Wilhelm S et al. Analysis of nanoparticle delivery to tumors. Nat. Rev. Mater. 1, 160104 (2016).

137. Ramanathan RK et al. Correlation between ferumoxytol uptake in tumor lesions by MRI and response to nanoliposomal irinotecan in patients with advanced solid tumors: a pilot study. Clin. Cancer Res. 23, 3638-3648 (2017). [PubMed: 28159813]

138. Lee $\mathrm{H}$ et al. 64Cu-MM-302 positron emission tomography quantifies variability of enhanced permeability and retention of nanoparticles in relation to treatment response in patients with metastatic breast cancer. Clin. Cancer Res. 23, 4190-4202 (2017). [PubMed: 28298546]

139. Mishra P, Nayak B \& Dey RK PEGylation in anti-cancer therapy: an overview. Asian J. Pharm. Sci. 11, 337-348 (2016).

140. Valcourt DM et al. Advances in targeted nanotherapeutics: from bioconjugation to biomimicry. Nano Res. 11, 4999-5016 (2018).

141. Riley RS \& Day ES Frizzled7 antibody-functionalized nanoshells enable multivalent binding for Wnt signaling inhibition in triple negative breast cancer cells. Small 13, 1-10 (2017).

142. Bartlett DW, Su H, Hildebrandt IJ, Weber WA \& Davis ME Impact of tumor-specific targeting on the biodistribution and efficacy of siRNA nanoparticles measured by multimodality in vivo imaging. Proc. Natl Acad. Sci. USA 104, 15549-15554 (2007). [PubMed: 17875985]

143. Wang C, Ye Y, Hochu GM, Sadeghifar H \& Gu Z Enhanced cancer immunotherapy by microneedle patch-assisted delivery of anti-PD1 antibody. Nano Lett. 16, 2334-2340 (2016). [PubMed: 26999507] In this paper, microneedle patches were designed to degrade and locally deliver anti-PD-1 antibodies in response to the acidic tumour microenvironment, demonstrating that $\mathrm{pH}$-responsive materials can enable precise control over the local delivery of immunotherapeutics to melanoma.

144. Liu $\mathrm{Y}$ et al. In situ modulation of dendritic cells by injectable thermosensitive hydrogels for cancer vaccines in mice. Biomacromolecules 15, 3836-3845 (2014). [PubMed: 25207465] 
145. Schmid D et al. T cell-targeting nanoparticles focus delivery of immunotherapy to improve antitumor immunity. Nat. Commun. 8, 1747 (2017). [PubMed: 29170511] In this paper, polymeric nanoparticles were loaded with immunotherapeutics and coated with antibody fragments to target specific $\mathrm{T}$ cells in circulation, showing that delivery via particle binding to endogenous immune cells induces stronger antitumour effects than free drug.

146. Mantovani A, Allavena P, Sica A \& Balkwill F Cancer-related inflammation. Nature 454, 436444 (2008). [PubMed: 18650914]

147. Mitchell MJ, Wayne EC, Rana K, Schaffer CB \& King MR TRAIL-coated leukocytes that kill cancer cells in the circulation. Proc. Natl. Acad. Sci. USA 111, 930-935 (2014). [PubMed: 24395803]

148. Wayne EC et al. TRAIL-coated leukocytes that prevent the bloodborne metastasis of prostate cancer. J. Control. Release 223, 215-223 (2016). [PubMed: 26732555]

149. Mitchell MJ, Chen CS, Ponmudi V, Hughes AD \& King MR E-Selectin liposomal and nanotubetargeted delivery of doxorubicin to circulating tumor cells. J. Control. Release 160, 609-617 (2012). [PubMed: 22421423]

150. Hajj KA \& Whitehead KA Tools for translation: non-viral materials for therapeutic mRNA delivery. Nat. Rev. Mater. 2, 1-17 (2017).

151. Zámecník J, Vargová L, Homola A, Kodet R \& Syková E Extracellular matrix glycoproteins and diffusion barriers in human astrocytic tumours. Neuropathol. Appl. Neurobiol. 30, 338-350 (2004). [PubMed: 15305979]

152. Lorenz $\mathrm{C}$ et al. Protein expression from exogenous mRNA: uptake by receptor-mediated endocytosis and trafficking via the lysosomal pathway. RNA Biol. 8, 627-636 (2011). [PubMed: 21654214]

153. Yin $\mathrm{H}$ et al. Non-viral vectors for gene-based therapy. Nat. Rev. Genet. 15, 541-555 (2014). [PubMed: 25022906]

154. Whitehead KA, Langer R \& Anderson DG Knocking down barriers: advances in siRNA delivery. Nat. Rev. Drug Discov. 8, 129-138 (2009). [PubMed: 19180106]

155. Oberli MA et al. Lipid nanoparticle assisted mRNA delivery for potent cancer immunotherapy. Nano Lett. 17, 1326-1335 (2017). [PubMed: 28273716] In this paper, a library of ionizable lipid nanoparticles was developed to deliver mRNA vaccines to immune cells and induce strong cytotoxic $\mathrm{T}$ cell responses. This article shows that nanoparticle design parameters, such as ionizable lipid structure and formulation parameters, modulate the ability of nanoparticles to successfully deliver mRNA vaccines.

156. Kranz LM et al. Systemic RNA delivery to dendritic cells exploits antiviral defence for cancer immunotherapy. Nature 534, 396-401 (2016). [PubMed: 27281205] This paper details the development of a nanoparticle-based RNA cancer vaccine that - through adjusting the negative net charge of nanoparticles rather than incorporating targeting ligands - preferentially targets dendritic cells in vivo upon systemic administration. The nanoparticle delivery system induced durable type I interferon-dependent antigen-specific immunity in mouse tumour models and induced strong antigen-specific $\mathrm{T}$ cell responses in patients with melanoma in a phase I doseescalation clinical trial.

157. Giacca M \& Zacchigna S VEGF gene therapy: therapeutic angiogenesis in the clinic and beyond. Gene Ther. 19, 622-629 (2012). [PubMed: 22378343]

158. Ramani K, Hassan Q, Venkiah B, Hasnain S \& Sarkar DP Site-specific gene delivery in vivo through engineered Sendai. Proc. Natl Acad. Sci. USA 95, 11886-11890 (1998). [PubMed: 9751760]

159. Nayak S \& Herzog RW Progress and prospects: immune responses to viral vectors. Gene Ther. 17, 295-304 (2010). [PubMed: 19907498]

160. Ziller A et al. Incorporation of mRNA in lamellar lipid matrices for parenteral administration. Mol. Pharm. 15, 642-651 (2018). [PubMed: 29232147]

161. US National Library of Medicine. ClinicalTrials.gov https://clinicaltrials.gov/ct2/show/ NCT02410733?term=NCT02410733\&rank=1 (2018).

162. Landesman-Milo D \& Peer D Toxicity profiling of several common RNAi-based nanomedicines: a comparative study. Drug Deliv. Transl Res. 4, 96-103 (2014). [PubMed: 25786620] 
163. Lv H, Zhang S, Wang B, Cui S \& Yan J Toxicity of cationic lipids and cationic polymers in gene delivery. J. Control. Release 114, 100-109 (2006). [PubMed: 16831482]

164. $\mathrm{Ma} \mathrm{Z}$ et al. Cationic lipids enhance siRNA-mediated interferon response in mice. Biochem. Biophys. Res. Commun. 330, 755-759 (2005). [PubMed: 15809061]

165. Kauffman KJ et al. Optimization of lipid nanoparticle formulations for mRNA delivery in vivo with fractional factorial and definitive screening designs. Nano Lett. 15, 7300-7306 (2015). [PubMed: 26469188]

166. Huotari J \& Helenius A Endosome maturation. EMBO J. 30, 3481-3500 (2011). [PubMed: 21878991]

167. Zelphati O \& Szoka FC Mechanism of oligonucleotide release from cationic liposomes. Proc. Natl Acad. Sci. USA 93, 11493-11498 (1996). [PubMed: 8876163]

168. Hafez IM, Maurer N \& Cullis PR On the mechanism whereby cationic lipids promote intracellular delivery of polynucleic acids. Gene Ther. 8, 1188-1196 (2001). [PubMed: 11509950]

169. Walsh C, Nguyen J, Tiffany M \& Szoka F Synthesis, characterization and evaluation of ionizable lysine-based lipids for siRNA delivery. Bioconjug. Chem. 24, 36-43 (2013). [PubMed: 23176544]

170. Chahal JS et al. An RNA nanoparticle vaccine against Zika virus elicits antibody and CD8+ T cell responses in a mouse model. Sci. Rep. 7, 252 (2017). [PubMed: 28325910]

171. Chahal JS et al. Dendrimer-RNA nanoparticles generate protective immunity against lethal Ebola, H1N1 influenza, and Toxoplasma gondii challenges with a single dose. Proc. Natl Acad. Sci. USA 113, E4133-E4142 (2016). [PubMed: 27382155]

172. Johansen P, Mohanan D, Martínez-Gómez JM, Kündig TM \& Gander B Lympho-geographical concepts in vaccine delivery. J. Control. Release 148, 56-62 (2010). [PubMed: 20562028]

173. Vartak A \& Sucheck S Recent advances in subunit vaccine carriers. Vaccines 4, 12 (2016).

174. Keler T, He L, Ramakrishna V \& Champion B Antibody-targeted vaccines. Oncogene 26, 37583767 (2007). [PubMed: 17530028]

175. Liu $\mathrm{H}$ et al. Structure-based programming of lymph-node targeting in molecular vaccines. Nature 507, 519-522 (2014). [PubMed: 24531764]

176. Moynihan KD et al. Eradication of large established tumors in mice by combination immunotherapy that engages innate and adaptive immune responses. Nat. Med. 22, 1402-1410 (2016). [PubMed: 27775706] This paper presents a powerful combination of immunotherapeutics, including a tumour antigen-targeting antibody, recombinant IL-2, an antiPD-1 antibody and a T cell vaccine, that is used to recruit several types of immune cell to elicit diverse immune responses and eradicate established tumours in vivo with substantial improvements over treatment with the individual agents.

177. Ishihara $\mathbf{J}$ et al. Matrix-binding checkpoint immunotherapies enhance antitumor efficacy and reduce adverse events. Sci. Transl Med. 9, eaan0401 (2017). [PubMed: 29118259] In this paper, matrix-binding molecular conjugates were used to locally deliver checkpoint blockade antibodies to tumours and to induce systemic antitumour immunity, providing a way to reduce the systemic side effects typically associated with these immunotherapeutics.

178. Vonderheide RH et al. Clinical activity and immune modulation in cancer patients treated with CP-870,893, a novel CD40 agonist monoclonal antibody. J. Clin. Oncol. 25, 876-883 (2007). [PubMed: 17327609]

179. Sanderson K et al. Autoimmunity in a phase I trial of a fully human anti-cytotoxic T-lymphocyte antigen-4 monoclonal antibody with multiple melanoma peptides and montanide ISA 51 for patients with resected stages III and IV melanoma. J. Clin. Oncol. 23, 741-750 (2005). [PubMed: 15613700]

180. Fransen MF, Van Der Sluis TC, Ossendorp F, Arens R \& Melief CJM Controlled local delivery of CTLA-4 blocking antibody induces CD8+T cell-dependent tumor eradication and decreases risk of toxic side effects. Clin. Cancer Res. 19, 5381-5389 (2013). [PubMed: 23788581]

181. Fransen MF, Sluijter M, Morreau H, Arens R \& Melief CJM Local activation of CD8 T cells and systemic tumor eradication without toxicity via slow release and local delivery of agonistic CD40 antibody. Clin. Cancer Res. 17, 2270-2280 (2011). [PubMed: 21389097] 
182. Rahimian S et al. Polymeric microparticles for sustained and local delivery of antiCD40 and antiCTLA-4 in immunotherapy of cancer. Biomaterials 61, 33-40 (2015). [PubMed: 25993015]

183. Graham BS et al. Immunization with cocktail of HIV-derived peptides in montanide ISA-51 is immunogenic, but causes sterile abscesses and unacceptable reactogenicity. PLOS ONE 5, e11995 (2010). [PubMed: 20706632]

184. Kleindienst P \& Brocker T Endogenous dendritic cells are required for amplification of $\mathrm{T}$ cell responses induced by dendritic cell vaccines in vivo. J. Immunol. 170, 2817-2823 (2003). [PubMed: 12626531]

185. Kim $\mathbf{J}$ et al. Injectable, spontaneously assembling, inorganic scaffolds modulate immune cells in vivo and increase vaccine efficacy. Nat. Biotechnol. 33, 64-72 (2015). [PubMed: 25485616] In this paper, injectable, spontaneously assembling silica rod-based scaffolds were engineered to release inflammatory signals and adjuvants as a means to recruit dendritic cells and increase vaccine efficacy compared with bolus controls, providing a minimally invasive approach that does not require the surgical implantation needed for other scaffold-based approaches.

186. Ali OA, Emerich D, Dranoff G \& Mooney DJ In situ regulation of DC subsets and T cells mediates tumor regression in mice. Sci. Transl Med. 1, 8ra19 (2010).

187. Gu L \& Mooney DJ Biomaterials and emerging anticancer therapeutics: engineering the microenvironment. Nat. Rev. Cancer 16, 56-66 (2016). [PubMed: 26694936]

188. Ali OA, Tayalia P, Shvartsman D, Lewen S \& Mooney D Inflammatory cytokines presented from polymer matrices differentially generate and activate DCs in situ. Adv. Funct. Mater 23, 46214628 (2013). [PubMed: 24688455]

189. Ali OA et al. Identification of immune factors regulating antitumor immunity using polymeric vaccines with multiple adjuvants. Cancer Res. 74, 1670-1681 (2014). [PubMed: 24480625]

190. Ali OA et al. The efficacy of intracranial PLG-based vaccines is dependent on direct implantation into brain tissue. J. Control. Release 154, 249-257 (2011). [PubMed: 21704093]

191. US National Library of Medicine. ClinicalTrials.gov https://clinicaltrials.gov/ct2/show/ NCT01753089?term=NCT01753089\&rank=1 (2018).

192. Schumacher TN \& Schreiber RD Neoantigens in cancer immunotherapy. Science 348, 69-74 (2015). [PubMed: 25838375]

193. Hori Y, Winans AM, Huang CC, Horrigan EM \& Irvine DJ Injectable dendritic cell-carrying alginate gels for immunization and immunotherapy. Biomaterials 29, 3671-3682 (2008). [PubMed: 18565578]

194. Koshy ST, Ferrante TC, Lewin SA \& Mooney DJ Injectable, porous, and cell-responsive gelatin cryogels. Biomaterials 35, 2477-2487 (2014). [PubMed: 24345735]

195. Bencherif SA et al. Injectable cryogel-based whole-cell cancer vaccines. Nat. Commun. 6, 1-13 (2015).

196. Li AW et al. A facile approach to enhance antigen response for personalized cancer vaccination. Nat. Mater. 17, 1-7 (2018).

197. Xia T et al. Polyethyleneimine coating enhances the cellular uptake of mesoporous silica nanoparticles and allows safe delivery of siRNA and DNA constructs. ACS Nano 3, 3273-3286 (2009). [PubMed: 19739605]

198. Garcia-Bennett AE et al. Synthesis toxicology and potential of ordered mesoporous materials in nanomedicine. Nanomedicine 6, 867-877 (2011). [PubMed: 21793677]

199. Song WJ, Du JZ, Sun TM, Zhang PZ \& Wang J Gold nanoparticles capped with polyethyleneimine for enhanced siRNA delivery. Small 6, 239-246 (2010). [PubMed: 19924738]

200. Oh YK et al. Enhanced adjuvanticity of interleukin-2 plasmid DNA administered in polyethylenimine complexes. Vaccine 21, 2837-2843 (2003). [PubMed: 12798625]

201. Wang $C$ et al. In situ formed reactive oxygen species - responsive scaffold with gemcitabine and checkpoint inhibitor for combination therapy. Sci. Transl Med. 10, 1-12 (2018).In this paper, injectable hydrogels were designed to degrade in response to reactive oxygen species in the tumour microenvironment for the sustained release of a combination chemotherapy and immunotherapy, demonstrating that hydrogels can enable high-precision control over the release kinetics of a combination of therapeutics simultaneously. 
202. Nathan C \& Cunningham-Bussel A Beyond oxidative stress: an immunologist's guide to reactive oxygen species. Nat. Rev. Immunol. 13, 349-361 (2013). [PubMed: 23618831]

203. Topalian SL et al. Survival, durable tumor remission, and long-term safety in patients with advanced melanoma receiving nivolumab. J. Clin. Oncol. 32, 1020-1030 (2014). [PubMed: 24590637]

204. Ye Y et al. A melanin-mediated cancer immunotherapy patch. Sci. Immunol. 2, aan5692 (2017).

205. Yu J et al. Microneedle-array patches loaded with hypoxia-sensitive vesicles provide fast glucoseresponsive insulin delivery. Proc. Natl Acad. Sci. USA 112, 8260-8265 (2015). [PubMed: 26100900]

206. Wallace A et al. Transforming growth factor- $\beta$ receptor blockade augments the effectiveness of adoptive T cell therapy of established solid cancers. Clin. Cancer Res. 14, 3966-3974 (2008). [PubMed: 18559619]

207. Stephan MT, Moon JJ, Um SH, Bersthteyn A \& Irvine DJ Therapeutic cell engineering with surface-conjugated synthetic nanoparticles. Nat. Med. 16, 1035-1041 (2010). [PubMed: 20711198] In this paper, T cells with surface-conjugated synthetic nanoparticles loaded with adjuvant improved donor cell stimulation and tumour elimination while minimizing systemic toxicity compared with free adjuvant administered systemically.

208. Stephan MT, Stephan SB, Bak P, Chen J \& Irvine DJ Synapse-directed delivery of immunomodulators using T cell-conjugated nanoparticles. Biomaterials 33, 5776-5787 (2012). [PubMed: 22594972]

209. Huang B et al. Active targeting of chemotherapy to disseminated tumors using nanoparticlecarrying T cells. Sci. Transl Med. 7, 291 ra94 (2015).

210. Rosenberg SA \& Restifo NP Adoptive cell transfer as personalized immunotherapy for human cancer. Science 348, 62-68 (2015). [PubMed: 25838374]

211. Smith $\mathrm{T}$ et al. In situ programming of leukaemia-specific T cells using synthetic DNA nanocarriers. Nat. Nanotechnol. 12, 813-820 (2017). [PubMed: 28416815] In this paper, a DNA nanoparticle platform was used to target $\mathrm{T}$ cells in the circulation and reprogramme them to express leukaemia-recognizing CAR genes as an alternative to ex vivo CAR T cell engineering.

212. Mangraviti A et al. Polymeric nanoparticles for nonviral gene therapy extend brain tumor survival in vivo. ACS Nano 9, 1236-1249 (2015). [PubMed: 25643235]

213. Smith TT et al. Biopolymers codelivering engineered T cells and STING agonists can eliminate heterogeneous tumors. J. Clin. Invest. 127, 2176-2191 (2017). [PubMed: 28436934]

214. Barrett DM, Singh N, Porter DL, Grupp SA \& June CH Chimeric antigen receptor therapy for cancer. Annu. Rev. Med. 65, 333-347 (2014). [PubMed: 24274181]

215. Rosenberg SA et al. Durable complete responses in heavily pretreated patients with metastatic melanoma using T cell transfer immunotherapy. Clin. Cancer Res. 17, 4550-4557 (2011). [PubMed: 21498393]

216. Robbins PF et al. Tumor regression in patients with metastatic synovial cell sarcoma and melanoma using genetically engineered lymphocytes reactive with NY-ESO-1. J. Clin. Oncol. 29, 917-924 (2011). [PubMed: 21282551]

217. Lamers CHJ et al. Treatment of metastatic renal cell carcinoma with CAIX CAR-engineered T cells: clinical evaluation and management of on-target toxicity. Mol. Ther. 21, 904-912 (2013). [PubMed: 23423337]

218. Yaghoubi S et al. Noninvasive detection of therapeutic cytolytic T cells with $18 \mathrm{~F}-\mathrm{FHBG}$ PET in a patient with glioma. Nat. Clin. Pract. Oncol. 6, 53-58 (2009). [PubMed: 19015650]

219. Kershaw $\mathrm{MH}$ et al. A phase I study on adoptive immunotherapy using gene-modified $\mathrm{T}$ cells for ovarian cancer. Clin. Cancer Res. 12, 6106-6115 (2006). [PubMed: 17062687]

220. Rhodes KR \& Green JJ Nanoscale artificial antigen presenting cells for cancer immunotherapy. Mol. Immunol. 98, 13-18 (2018). [PubMed: 29525074]

221. Meyer RA et al. Biodegradable nanoellipsoidal artificial antigen presenting cells for antigen specific T-cell activation. Small 11, 1519-1525 (2015). [PubMed: 25641795]

222. Kosmides AK et al. Biomimetic biodegradable artificial antigen presenting cells synergize with PD-1 blockade to treat melanoma. Biomaterials 118, 16-26 (2017). [PubMed: 27940380] 
223. Day CP, Merlino G \& Van Dyke T Preclinical mouse cancer models: a maze of opportunities and challenges. Cell 163, 39-53 (2015). [PubMed: 26406370]

224. Mestas J \& Hughes CC Of mice and not men: differences between mouse and human immunology. J. Immunol. 172, 2731-2738 (2004). [PubMed: 14978070]

225. Tao L \& Reese TA Making mouse models that reflect human immune responses. Trends Immunol. 38, 181-193 (2017). [PubMed: 28161189]

226. Sadun RE et al. Immune signatures of murine and human cancers reveal unique mechanisms of tumor escape and new targets for cancer immunotherapy. Clin. Cancer Res. 13, 4016-4025 (2007). [PubMed: 17606736]

227. Hua S, de Matos MBC, Metselaar JM \& Storm G Current trends and challenges in the clinical translation of nanoparticulate nanomedicines: pathways for translational development and commercialization. Front. Pharmacol. 9, 1-14 (2018). [PubMed: 29387012]

228. Bulbake U, Doppalapudi S, Kommineni N \& Khan W Liposomal formulations in clinical use: an updated review. Pharmaceutics 9, 1-33 (2017).

229. Bobo D, Robinson KJ, Islam J, Thurecht KJ \& Corrie SR Nanoparticle-based medicines: a review of FDA-approved materials and clinical trials to date. Pharm. Res. 33, 2373-2387 (2016). [PubMed: 27299311]

230. Danhier F et al. PLGA-based nanoparticles: an overview of biomedical applications. J. Control. Release 161, 505-522 (2012). [PubMed: 22353619]

231. Gust $\mathrm{J}$ et al. Endothelial activation and blood-brain barrier disruption in neurotoxicity after adoptive immunotherapy with CD19 CAR-T cells. Cancer Discov. 7, 1404-1419 (2017). [PubMed: 29025771]

232. Ren $\mathrm{J}$ et al. A versatile system for rapid multiplex genome-edited CAR T cell generation. Oncotarget 8, 17002-17011 (2017). [PubMed: 28199983]

233. Singh N, Shi J, June CH \& Ruella M Genome-editing technologies in adoptive T cell immunotherapy for cancer. Curr. Hematol. Malig. Rep. 12, 522-529 (2017). [PubMed: 29039115]

234. Liu $\mathrm{H}$ et al. Use of angiotensin system inhibitors is associated with immune activation and longer survival in nonmetastatic pancreatic ductal adenocarcinoma. Clin. Cancer Res. 23, 5959-5969 (2017). [PubMed: 28600474]

235. US National Library of Medicine. ClinicalTrials.gov https://clinicaltrials.gov/ct2/show/ NCT01821729?term=NCT01821729\&rank=1 (2017).

236. Chauhan VP et al. Angiotensin inhibition enhances drug delivery and potentiates chemotherapy by decompressing tumour blood vessels. Nat. Commun. 4, 2516 (2013). [PubMed: 24084631]

237. Alvey $\mathrm{C}$ et al. SIRPA-inhibited, marrow-derived macrophages engorge, accumulate, and differentiate in antibody-targeted regression of solid tumors. Curr. Biol. 27, 2065-2077 (2017). [PubMed: 28669759]

238. Miller MA et al. Tumour-associated macrophages act as a slow-release reservoir of nanotherapeutic Pt(IV) pro-drug. Nat. Commun. 6, 8692 (2015). [PubMed: 26503691]

239. Sharei A et al. Ex vivo cytosolic delivery of functional macromolecules to immune cells. PLOS ONE 10, e0118803 (2015). [PubMed: 25875117]

240. Szeto GL et al. Microfluidic squeezing for intracellular antigen loading in polyclonal B cells as cellular vaccines. Sci. Rep. 5, 10276 (2015). [PubMed: 25999171]

241. Sharei A et al. A vector-free microfluidic platform for intracellular delivery. Proc. Natl Acad. Sci. USA 110, 2082-2087 (2013). [PubMed: 23341631]

242. Stewart MP et al. In vitro and ex vivo strategies for intracellular delivery. Nature 538, 183-192 (2016). [PubMed: 27734871]

243. Perica $\mathrm{K}$ et al. Magnetic field-induced t cell receptor clustering by nanoparticles enhances t cell activation and stimulates antitumor activity. ACS Nano 8, 2252-2260 (2014). [PubMed: 24564881]

244. Fadel TR et al. A carbon nanotube-polymer composite for T cell therapy. Nat. Nanotechnol. 9 , 639-647 (2014). [PubMed: 25086604] 
245. Sunshine JC, Perica K, Schneck JP \& Green JJ Particle shape dependence of CD8+ T cell activation by artificial antigen presenting cells. Biomaterials 35, 269-277 (2014). [PubMed: 24099710]

246. Cheung AS, Zhang DKY, Koshy ST \& Mooney DJ Scaffolds that mimic antigen-presenting cells enable ex vivo expansion of primary T cells. Nat. Biotechnol. 36, 160-169 (2018). [PubMed: 29334370] In this paper, scaffolds containing silica microrods were coated with APC-mimetic ligands to induce T cell expansion ex vivo. This technology is five times more effective at expanding CD19 CAR T cells than a traditional ex vivo approach, providing a more efficient means of preparing $\mathrm{T}$ cells for immunotherapy.

247. Andorko JI, Hess KL, Pineault KG \& Jewell CM Intrinsic immunogenicity of rapidly-degradable polymers evolves during degradation. Acta Biomater. 32, 24-34 (2016). [PubMed: 26708710]

248. Andorko JI, Pineault KG \& Jewell CM Impact of molecular weight on the intrinsic immunogenic activity of poly(beta amino esters). J. Biomed. Mater. Res. A 105, 1219-1229 (2017). [PubMed: 27977902] 


\section{Cytokine release syndrome}

Rapid release of cytokines leading to adverse symptoms such as increased heartbeat, nausea and low blood pressure. 


\section{Vascular leak syndrome}

Increased vascular permeability that causes fluids from capillary vessels to enter tissues, which can lead to organ damage.

\section{Dendritic cell}

A type of antigen-presenting cell whose main function is to present antigens to T cells to modulate the immune system. 


\section{Regulatory $\mathbf{T}$ cells}

A $\mathrm{T}$ cell population that maintains tolerance to self-antigens and prevents autoimmune disease.

\section{Macrophages}

A type of immune cell found at sites of infection and in tumour microenvironments.

Natural killer (NK) cells

A type of lymphocyte that can bind to and kill tumour cells.

\section{Lymphocytes}

A type of white blood cell found in the lymphatic system.

\section{$\mathrm{CD4}^{+} \mathrm{T}$ cells}

T helper cells that regulate immune responses.

\section{$\mathrm{CD8}^{+} \mathrm{T}$ cells}

Cytotoxic T cells that kill abnormal cells.

\section{Antigen-presenting cells}

(APCs). Immune cells that present antigens to $\mathrm{T}$ cells to modulate immune responses. 


\section{B cell aplasia}

An adverse side effect of chimeric antigen receptor $\mathrm{T}$ cell therapy characterized by low numbers of B cells. 


\section{Click chemistry}

A type of reaction commonly used for bioconjugation of molecules to delivery systems. 


\section{Dendrimers}

A type of synthetic polymer with a branch-like structure. 


\section{Patient-derived xenograft (PDX) models}

Cancer models in which patient-derived tumour tissue or cells are implanted into immunocompromised mice. 


\section{RELATED LINKS}

ClinicalTrials.gov: https://www.clinicaltrials.gov/

Roche partners with sQZ: https://sqzbiotech.com/documents/

SQZ_Roche_Agreement_Press_Release_Final.pdf 

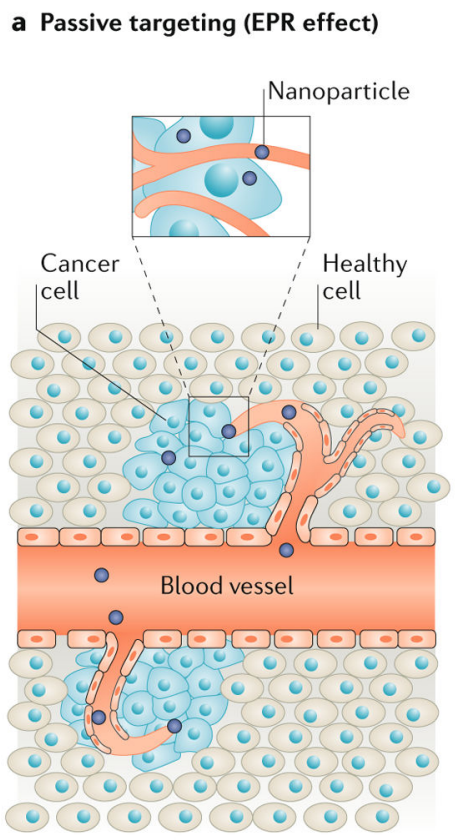

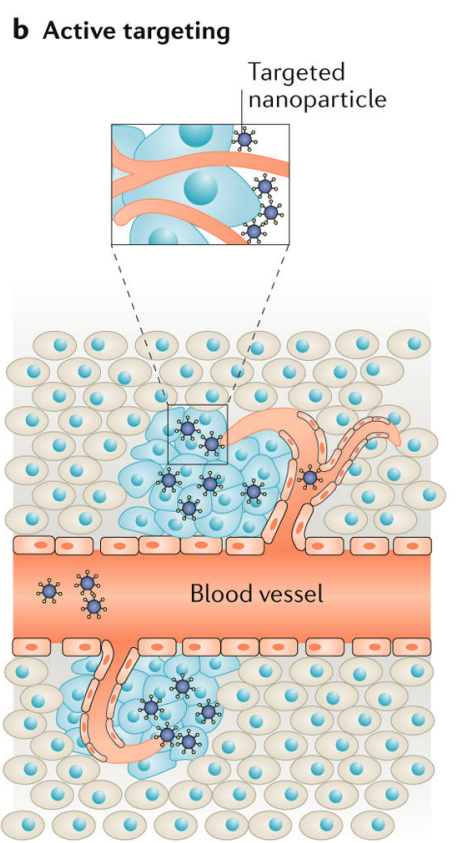

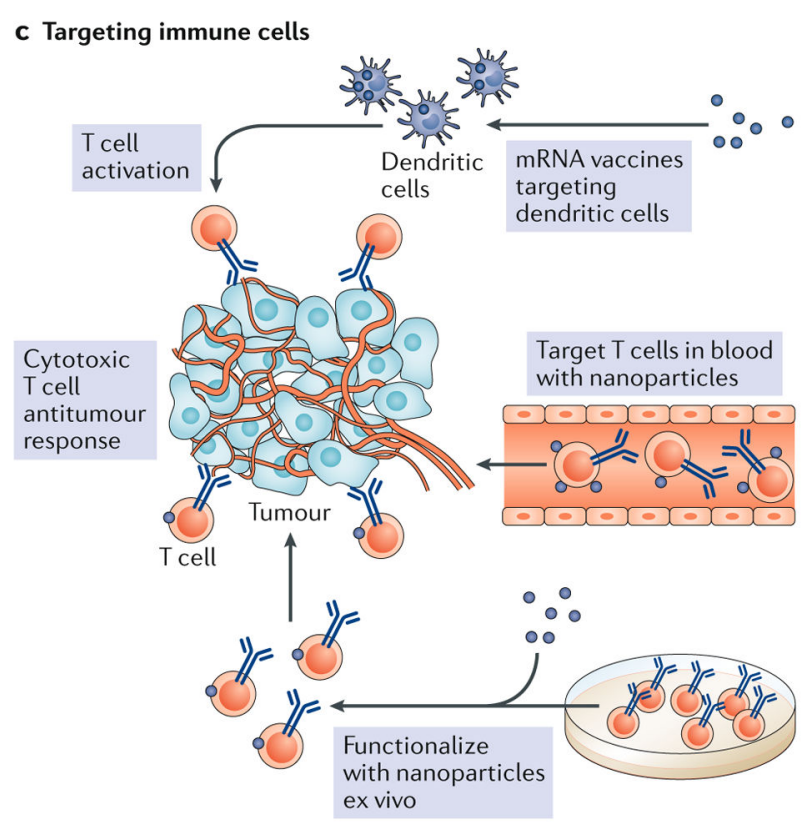

Fig. 1 I. Paradigms in cancer nanomedicine.

$\mathbf{a}, \mathbf{b}$ | For decades, cancer nanomedicine has focused on the delivery of therapeutics into tumours via passive targeting mechanisms by exploiting the enhanced permeation and retention (EPR) effect mediated through leaky tumour vessels (part a) or active targeting mechanisms in which nanoparticles are functionalized with targeting ligands that specifically bind receptors on the surfaces of tumour cells (part b).c I New paradigms that use nanomedicine to engage immune cells are emerging. These nanomedicines induce cytotoxic antitumour $\mathrm{T}$ cell responses rather than deliver drugs to the tumour. Strategies that use these new approaches include nucleic acid vaccines and the direct targeting of $\mathrm{T}$ cells in the circulation or ex vivo. Parts $\mathbf{a}$ and $\mathbf{b}$ are adapted with permission from REF. ${ }^{133}$, Elsevier. Part $\mathbf{c}$ is adapted from REF. ${ }^{187}$, Springer Nature Limited. 


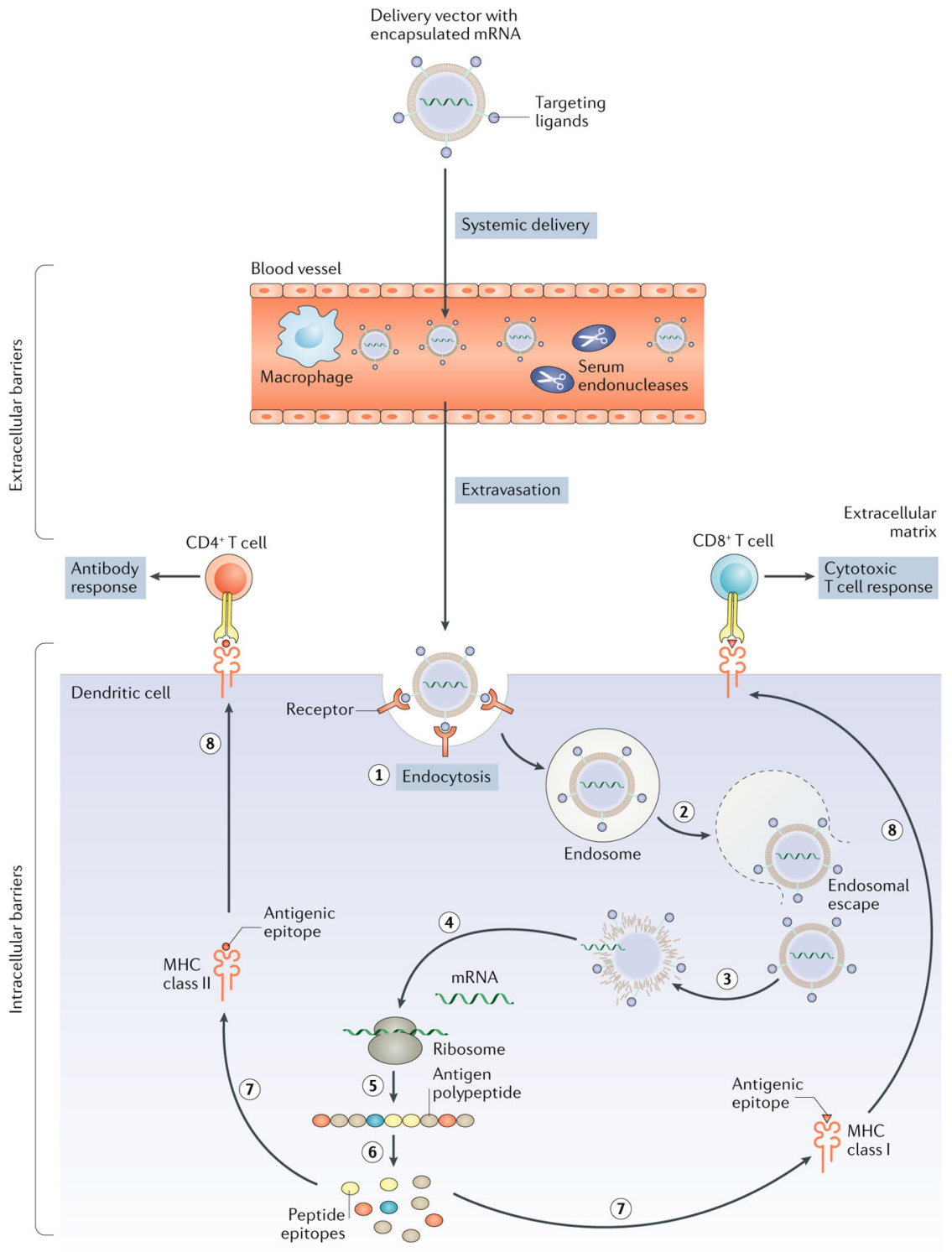

Fig. 2 I. Barriers to mRNA cancer vaccine delivery to dendritic cells.

Various non-viral vectors can be engineered to deliver mRNA to dendritic cells in vivo.

These vectors need to prevent degradation of the mRNA by serum endonucleases and evade macrophage detection (which could be achieved by chemical modifications and encapsulation of nucleic acids). They also need to avoid renal clearance from the blood and prevent nonspecific interactions (by using polyethylene glycol (PEG) or through particle design). Moreover, these vectors need to extravasate from the bloodstream to reach dendritic cells in target tissues and mediate dendritic cell entry and endosomal escape. Once mRNA is in the cytosol, it is translated into the antigenic peptide, which is then processed into smaller peptide epitopes that bind to the major histocompatibility complex (MHC) class I or class II molecules. The MHCs are trafficked to the cell surface, where they present their antigenic epitopes to either $\mathrm{CD}^{+}$(cytotoxic) $\mathrm{T}$ cells or $\mathrm{CD}^{+}$(helper) $\mathrm{T}$ cells, leading to a cytotoxic $\mathrm{T}$ 
cell response or an antigen-specific antibody response, respectively. The order of the steps of mRNA entry and processing is shown by sequential numbering. Figure adapted from REFS $^{153,154}$, Springer Nature Limited. 
a Lipid nanoparticle

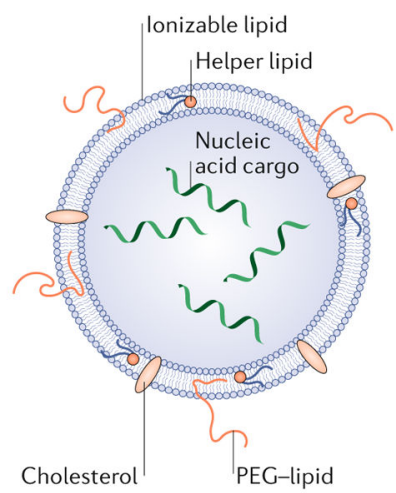

C lonizable lipid-like materials

C12-200

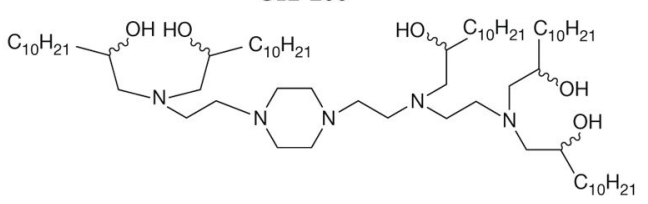

b Off-the-shelf lipids
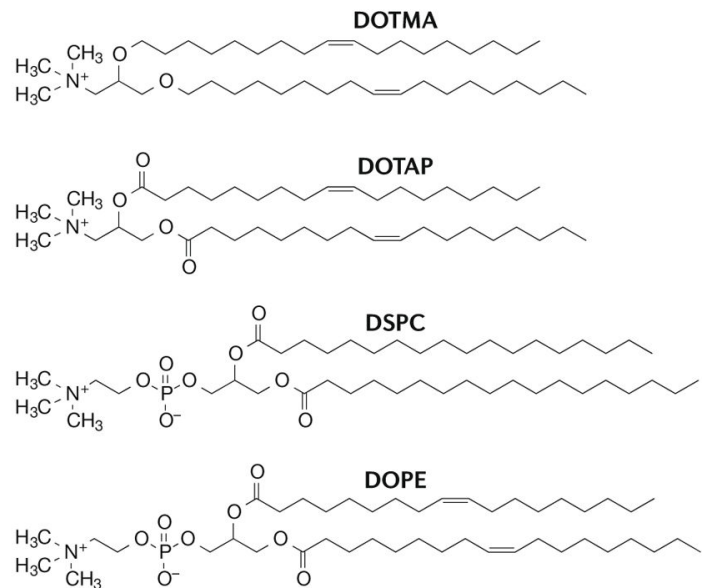

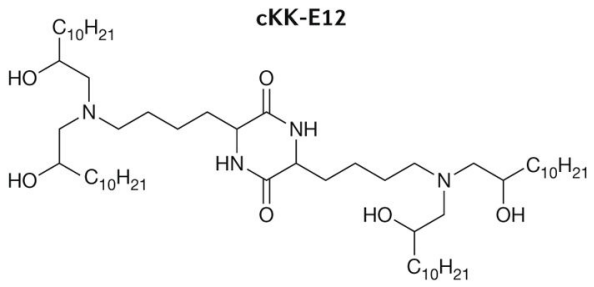

d Amphiphilic peptide-vaccine conjugate

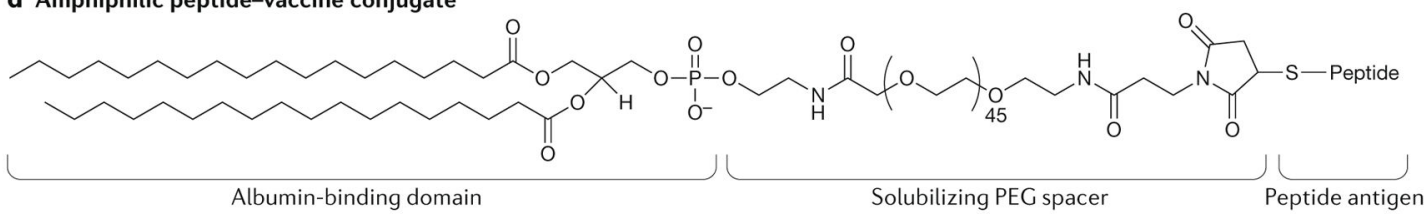

e Matrix-binding checkpoint inhibitor conjugate

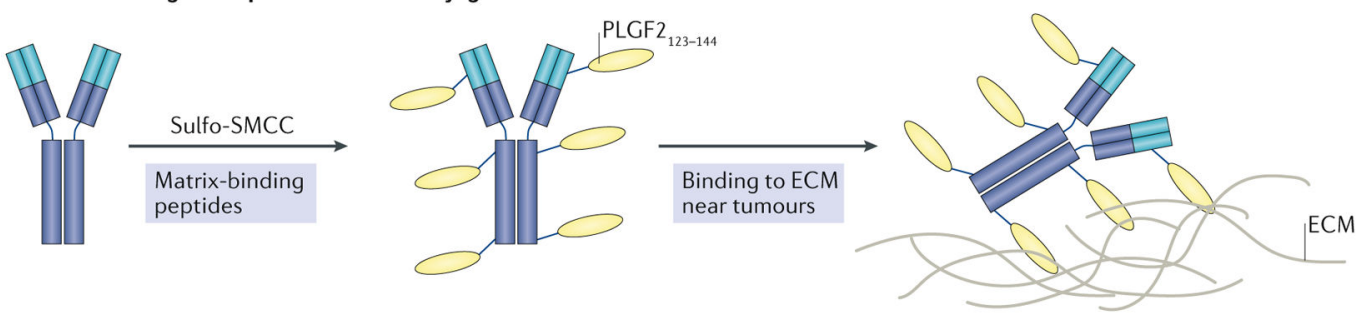

Fig. 3 I. Nanoparticles and nanoscale conjugates and delivery systems for cancer immunotherapy.

a I Lipid nanoparticles typically consist of an ionizable lipid, a helper lipid, cholesterol and polyethylene glycol (PEG)-lipid. The nucleic acids are incorporated into the hydrophilic interior of the nanoparticle. b I Structures of off-the-shelf lipids that have been investigated for nucleic acid delivery and, more recently, for mRNA vaccines are shown. Also included is the structure of DOPE (1,2-dioleoyl-sn-glycero-3-phosphoethanolamine), a helper lipid that imparts efficacy to lipid nanoparticle formulations, $\mathbf{c}$ । Structures of ionizable, lipid-like materials designed through combinatorial chemistry techniques for improved in vivo mRNA delivery with reduced toxicity. $\mathbf{d}$ I The structure of an amphiphilic peptide-vaccine 
conjugate designed to bind to albumin in the bloodstream for improved delivery to lymph nodes is shown. e I A matrix-binding checkpoint inhibitor conjugate that has improved retention in the peritumoural space to trigger an immune response. The checkpoint inhibitor is bound to a peptide of placental growth factor 2 (PLGF2) using an amine-to-sulfhydryl crosslinker. The PLGF2 peptide mediates binding to proteins in the extracellular matrix (ECM). DOTAP, 1,2-dioleoyl-3-trimethylammonium-propane; DOTMA, 1,2-di- $O$-octadecenyl-3-trimethylammonium-propane; DSPC, 1,2-distearoyl-sn-glycero-3-

phosphocholine; SMCC,sulfosuccinimidyl 4-(N-maleimidomethyl)cyclohexane-1carboxylate. Part $\mathbf{a}$ is adapted from REF. ${ }^{150}$, Springer Nature Limited. Part $\mathbf{d}$ is adapted from REF. ${ }^{175}$, Springer Nature Limited. Part $\mathbf{e}$ is adapted with permission from REF. ${ }^{177}$, Science/ AAAS. 


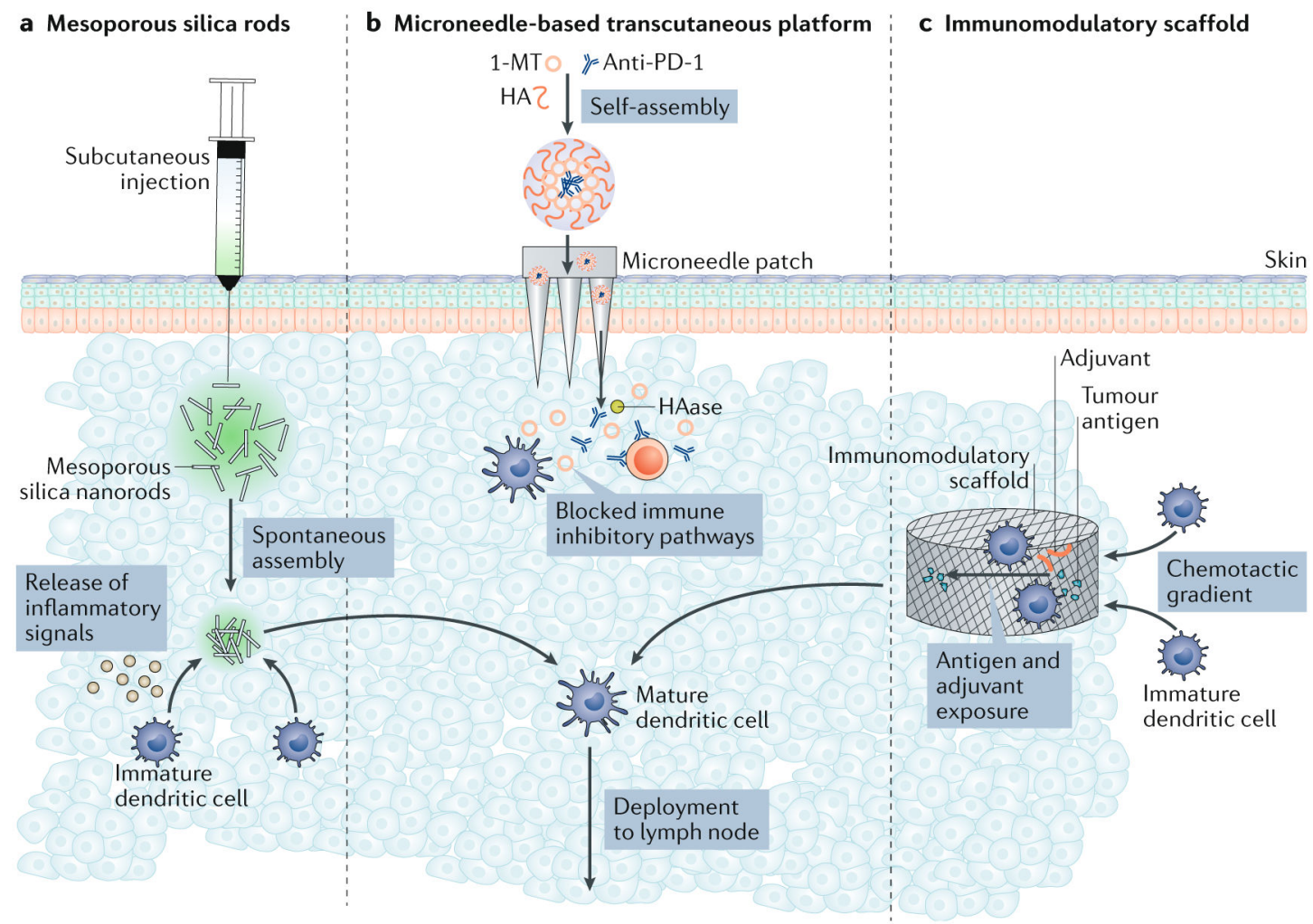

Fig. 4 I. Biomaterials for localized delivery of cancer immunotherapy.

a I Mesoporous silica rods (MSRs) spontaneously assemble in vivo and recruit host cells for maturation. A phosphate buffered saline (PBS) dispersion of MSRs is injected into the subcutaneous tissue of mice to form a pocket. After diffusion of PBS from the pocket, in situ spontaneous assembly of MSRs, analogous to the random assembly of thrown matchsticks, results in the formation of 3D interparticle spaces into which host cells can be recruited and educated by the therapeutics delivered with the MSRs. Educated cells can then emigrate from the structure to interact with other immune cells. b I In another approach, a microneedle-based transcutaneous platform loaded with self-assembled immunotherapeutic nanocarriers was used. Nanoparticle-mediated encapsulation and release of the indoleamine 2,3-dioxygenase (IDO) inhibitor 1-MT and an anti-programmed cell death 1 (PD-1) antibody from self-assembled nanoparticles are mediated through a multistep process. First, the 1-MT is conjugated to hyaluronan (HA), then this conjugate self-assembles around the anti-PD-1 antibody to form a nanoparticle for delivery. Once it has been delivered, the nanoparticle is dissociated by hyaluronidase (HAase), resulting in release of the drugs into the tumour microenvironment. These therapeutics can be delivered using microneedles as shown. c I A subcutaneously delivered porous biomaterial scaffold that releases a chemoattractant recruits naive dendritic cells into its void space. Scaffold-resident dendritic cells are exposed to tumour antigens and adjuvants, resulting in increased presentation of peptides on major histocompatibility complex (MHC)-peptide complexes and phenotypic maturation. Mature dendritic cells traffic out of the scaffold to lymph nodes, where they can stimulate antitumour immunity. 
a Surface-conjugated synthetic nanoparticles

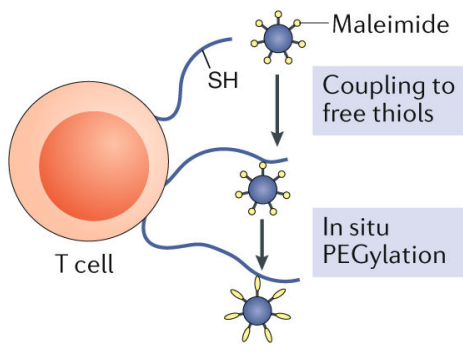

b DNA nanocarriers

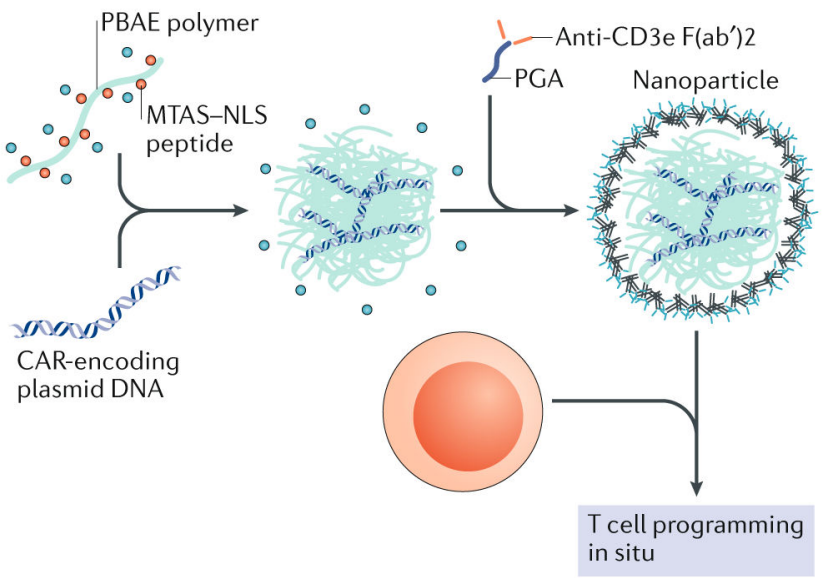

c aAPC design T cell-stimulating ligands
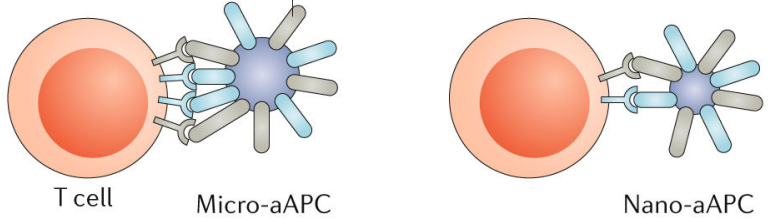

Nano-aAPC

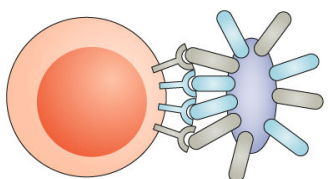

Ellipsoidal nano-aAPC

Fig. 5 I. Delivery approaches for $\mathbf{T}$ cell-based immunotherapy.

a I Therapeutic T cell engineering via surface-conjugated synthetic nanoparticles.

Nanoparticles can be stably conjugated to the surfaces of $\mathrm{T}$ cells via cell surface thiols for improved adoptive T cell therapy. b I Programming T cells in situ via DNA nanocarriers. A schematic of the $\mathrm{T}$ cell-targeted DNA nanocarrier used to programme $\mathrm{T}$ cells, including fabrication of the poly ( $\beta$-amino ester) (PBAE) nanoparticles for encapsulation of DNA, is shown. Nanoparticles are then coated with polyglutamic acid (PGA) to shield the positive charge and functionalized with an anti-CD3 antibody to mediate binding to T cells in the bloodstream. A nuclear localization signal (NLS) and a microtubule-associated sequence (MTAS) can be added to target the DNA to the nucleus. $\mathbf{c}$ I Strategies for synthetic artificial antigen-presenting cell (aAPC) design. A representation of a classic micro-aAPC with surface-bound signal 1 (anti-CD3 antibody, major histocompatibility complex (MHC) multimer and other components; shown in blue) and signal 2 (anti-CD28 antibody, anti-4-1BB antibody and other components; shown in grey) molecules to initiate T cell expansion and activation is shown. Nanoscale aAPCs are less efficient T cell activators but may outperform micro-aAPCs in vivo owing to their transport properties. Recent findings suggest that ellipsoidal nano-aAPCs activate T cells more efficiently than spherical nanoaAPCs owing to increased contact surface area. CAR, chimeric antigen receptor; PEG, polyethylene glycol. Part $\mathbf{a}$ is adapted from REF. ${ }^{207}$, Springer Nature Limited. Part $\mathbf{b}$ is adapted from REF. ${ }^{211}$, Springer Nature Limited. Part $\mathbf{c}$ is adapted with permission from REF. $^{220}$, Elsevier. 
Riley et al.

Page 52

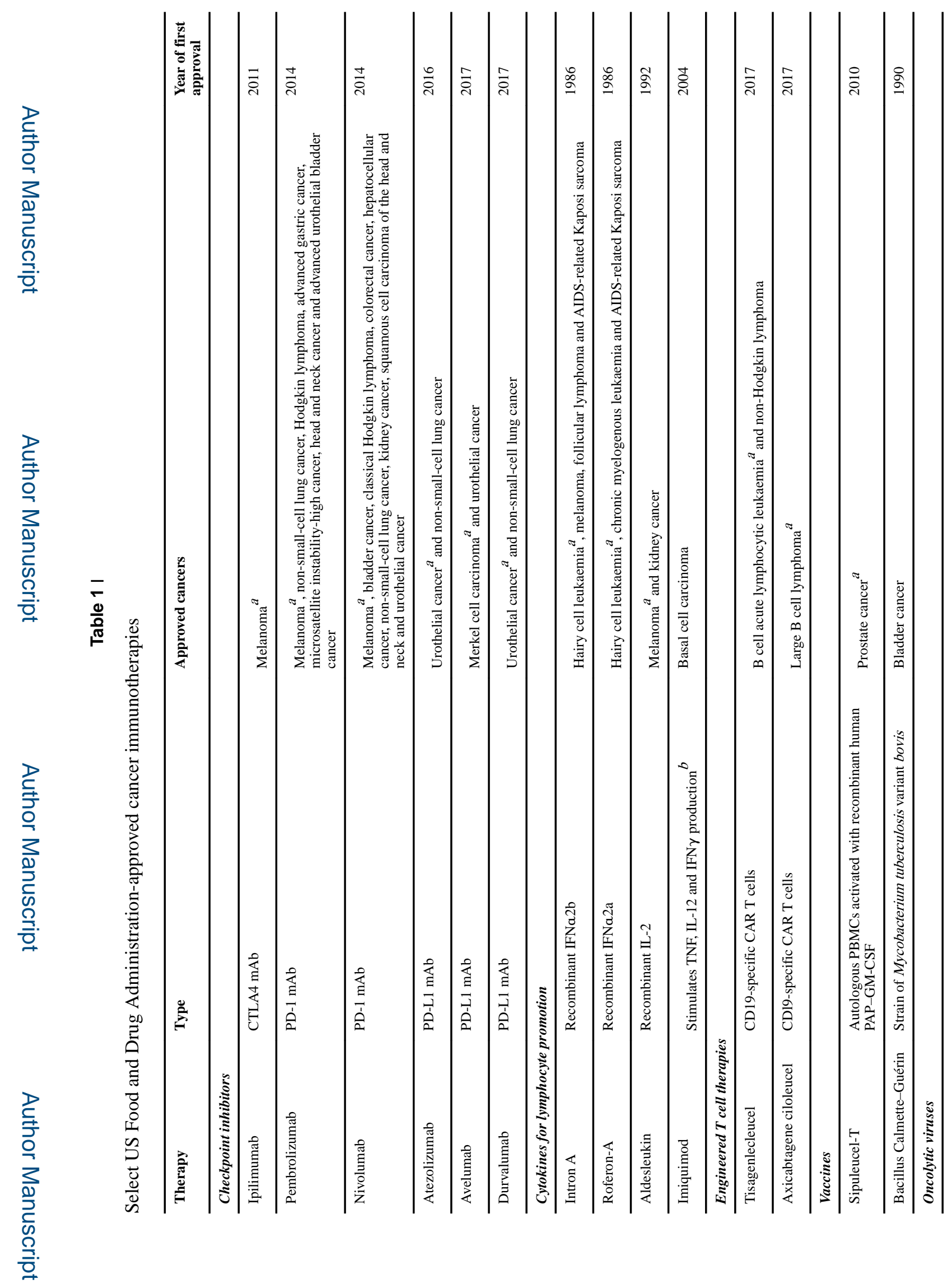

Nat Rev Drug Discov. Author manuscript; available in PMC 2019 March 11. 
Riley et al.

Page 53

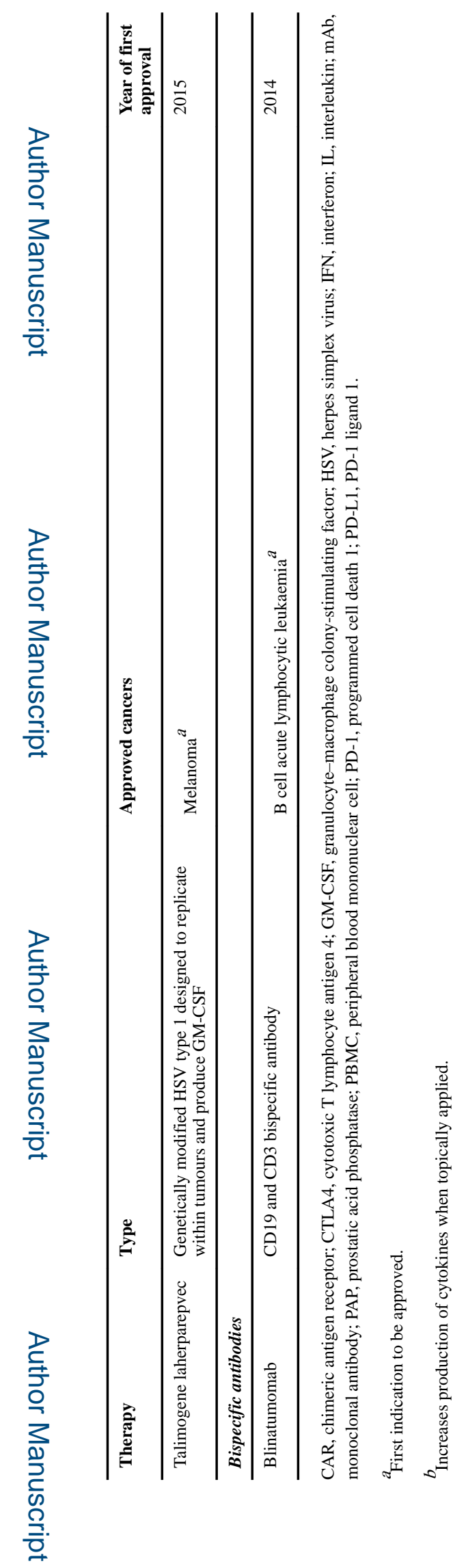

Nat Rev Drug Discov. Author manuscript; available in PMC 2019 March 11. 


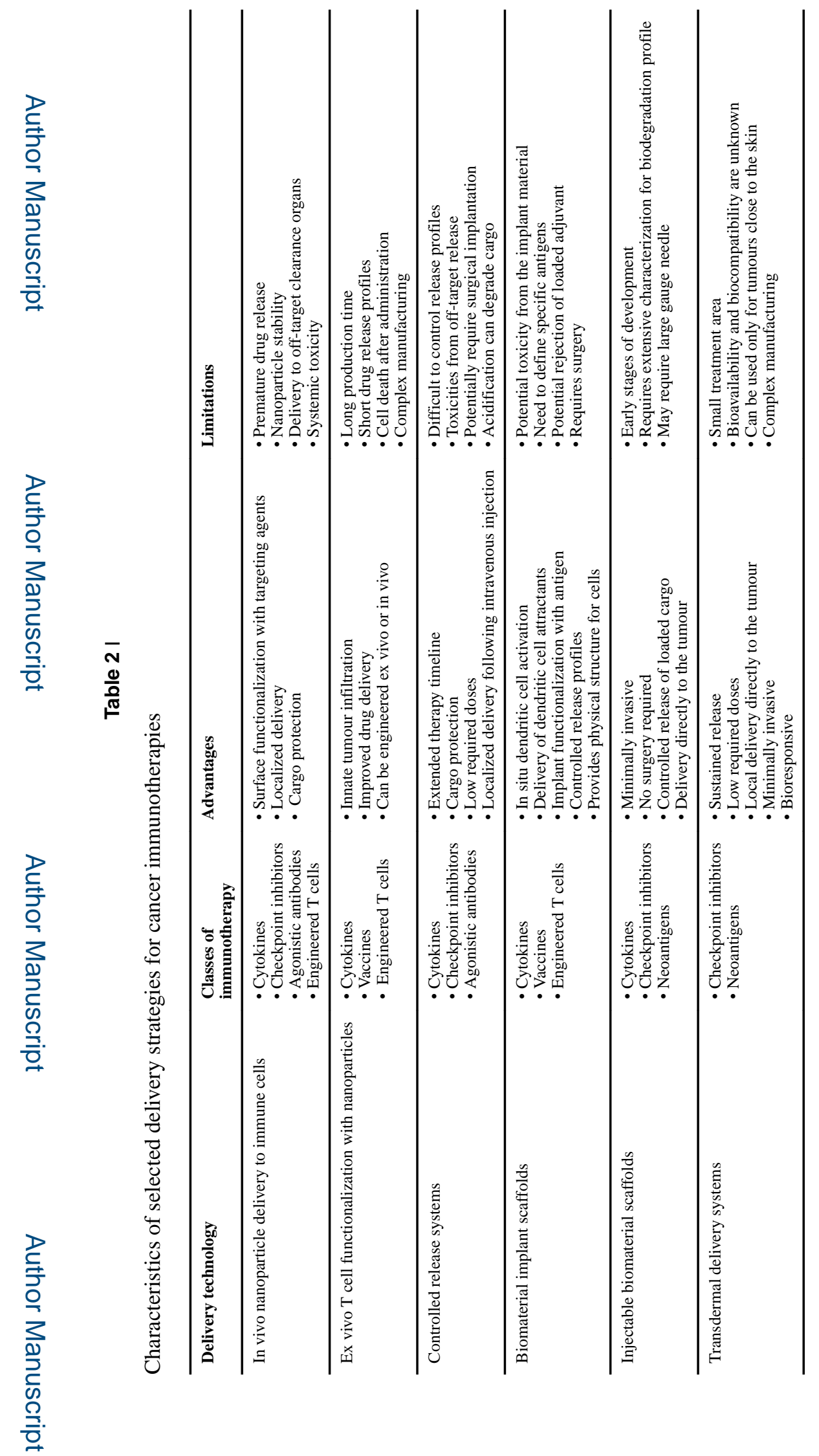

Nat Rev Drug Discov. Author manuscript; available in PMC 2019 March 11. 